\title{
DISARM Early Warning System for Wildfires in the Eastern Mediterranean
}

\author{
Vassiliki Kotroni ${ }^{1, *(\mathbb{D})}$, Constantinos Cartalis ${ }^{2}$, Silas Michaelides ${ }^{3}{ }^{\mathbb{D}}$, Julia Stoyanova ${ }^{4}$, \\ Fillipos Tymvios ${ }^{5}$, Antonis Bezes ${ }^{1}$, Theodoros Christoudias ${ }^{3} \mathbb{D}$, Stavros Dafis ${ }^{1,6} \mathbb{D}$, \\ Christos Giannakopoulos ${ }^{1}$, Theodore M. Giannaros ${ }^{1}$ (D), Christo Georgiev ${ }^{4}$, \\ Athanasios Karagiannidis ${ }^{1}$ (D), Anna Karali ${ }^{1}$, Ioannis Koletsis ${ }^{1}$, Konstantinos Lagouvardos ${ }^{1}$, \\ Ioannis Lemesios $^{1}$, Thaleia Mavrakou ${ }^{2}$ (D), Katerina Papagiannaki ${ }^{1} \mathbb{D}$, Anastasios Polydoros ${ }^{2}$ (D) \\ and Yiannis Proestos 3 \\ 1 Institute for Environmental Research and Sustainable Development, National Observatory of Athens, \\ 15236 Athens, Greece; antbezes@noa.gr (A.B.); sdafis@noa.gr (S.D.); cgiannak@meteo.noa.gr (C.G.); \\ thgian@noa.gr (T.M.G.); thankar@live.com (A.K.); akarali@noa.gr (A.K.); koletsis@noa.gr (I.K.); \\ lagouvar@noa.gr (K.L.); jlemesios@noa.gr (I.L.); katpap@noa.gr (K.P.) \\ 2 Department of Physics, National and Kapodistrian University of Athens, 15771 Athens, Greece; \\ ckartali@phys.uoa.gr (C.C.); thmavrakou@phys.uoa.gr (T.M.); apoly@phys.uoa.gr (A.P.) \\ 3 The Cyprus Institute, Nicosia 2121, Cyprus; s.michaelides@cyi.ac.cy (S.M.); t.christoudias@cyi.ac.cy (T.C.); \\ y.proestos@cyi.ac.cy (Y.P.) \\ 4 National Institute of Meteorology and Hydrology, 1784 Sofia, Bulgaria; Julia.Stoyanova@meteo.bg (J.S.); \\ christo.georgiev@meteo.bg (C.G.) \\ 5 Department of Meteorology, Nicosia 1086, Cyprus; filippos.tymvios@gmail.com \\ 6 LMD/IPSL, CNRS UMR 8539, École Polytechnique, Sorbonne Universités, 91128 Palaiseau, France \\ * Correspondence: kotroni@meteo.noa.gr
}

Received: 1 July 2020; Accepted: 14 August 2020; Published: 18 August 2020

check for updates

\begin{abstract}
This paper discusses the main achievements of DISARM (Drought and fIre ObServatory and eArly waRning system) project, which developed an early warning system for wildfires in the Eastern Mediterranean. The four pillars of this system include (i) forecasting wildfire danger, (ii) detecting wildfires with remote sensing techniques, (iii) forecasting wildfire spread with a coupled weather-fire modeling system, and (iv) assessing the wildfire risk in the frame of climate change. Special emphasis is given to the innovative and replicable parts of the system. It is shown that for the effective use of fire weather forecasting in different geographical areas and in order to account for the local climate conditions, a proper adjustment of the wildfire danger classification is necessary. Additionally, the consideration of vegetation dryness may provide better estimates of wildfire danger. Our study also highlights some deficiencies of both EUMETSAT (Exploitation of Meteorological Satellites) and LSA-SAF (Satellite Application Facility on Land Surface Analysis) algorithms in their skill to detect wildfires over islands and near the coastline. To tackle this issue, a relevant modification is proposed. Furthermore, it is shown that IRIS, the coupled atmosphere-fire modeling system developed in the frame of DISARM, has proven to be a valuable supporting tool in fire suppression actions. Finally, assessment of the wildfire danger in the future climate provides the necessary context for the development of regional adaptation strategies to climate change.
\end{abstract}

Keywords: wildfires; fire danger; fire spread forecasting; remote sensing of wildfire activity; early warning systems 


\section{Introduction}

Extreme wildfire events have affected many areas around the world over the past decades, causing not only casualties (civilians and fire respondents), but also extensive damages to livestock, infrastructure, and the ecosystem. For instance, the 2018 Camp Fire in California was the deadliest and most destructive wildfire in the history of the State, counting 85 fatalities, more than 18,000 damaged structures, and 62,053 ha of area burnt [1]. In Australia, destructive bushfires across the years have caused extended losses of both human and animal lives. Among them, it is worth mentioning the 2009 wildfires in Victoria, counting 173 fatalities and 450,000 ha of burnt area [2], while in January 2020, catastrophic bushfires resulted in more than 1 billion losses of animal life and 11,000,000 ha of area burnt. In the latter case, the States of New South Wales and Victoria had been the most affected areas.

In southern Europe, the Mediterranean climate favors both the ignition and the spread of wildfires. For instance, Portugal has suffered severe wildfires in 2003, 2005, and 2017 [3,4] that burnt 425,839 ha, $339,088 \mathrm{ha}$, and 470,000 ha of land (115 casualties in total), respectively. In south Greece, a wildfire in August 2007 resulted in a loss of 84 human lives, more than 3000 destroyed houses, and 270,000 ha of burnt area [5]. However, the deadliest event ever (102 casualties) has been the recent wildfire in eastern Attica (July 2018), which burned an area of $~ 1250$ ha [6]. In a recent study of Ribeiro et al. [7], 16 extreme wildfire events in six countries were discussed. The authors highlighted the importance of raising the awareness of the citizens and the communities in coping with wildfires through improved education and well-distributed information.

Investigation of the spatiotemporal variability of fire weather conditions over the last decades in the Euro-Mediterranean area has attracted many researchers' interest (among others, [8-11]). For example, Giannaros et al. [11] has recently provided a spatiotemporal mapping of fire weather conditions in Europe and the Mediterranean, aiming to investigate potential long-term trends of fire weather conditions (period 1987-2016). The authors reported an increasing occurrence of extreme fire weather conditions over the Iberian Peninsula and eastern Balkans, and decreasing trends over the southeast Mediterranean. The investigation of the trends of fire weather extremes in the current and in the future climate is of paramount importance, since they directly affect the planning of fire prevention, suppression, and all the related management strategies.

Given the high dependence of wildfires on weather and climate [12], many studies have focused their interest in various fields such as: The assessment of the expected changes of fire risk, the potential for large wildfires, the expected impacts on fire intensity and occurrence, wildfire suppression, and burned areas. These studies are mainly based on the analysis of climate model simulations under various emission scenarios [13-16]. The observed trend towards warmer and drier conditions in southern Europe and the Mediterranean is expected to persist over the next decades, possibly leading to increased length and severity of the fire season, area at risk, and probability of large fires [17]. The link between climate and fire is often analyzed under the intermediate fire-productivity hypothesis $[18,19]$. According to this, ecosystems can be arranged in an aridity-productivity gradient, along which, fire is constrained either by fuel availability on one extreme (fuel-driven fires), or by the occurrence of conditions conducive to fire on the other (drought-driven fires). Moreover, several studies assume that in southern Europe, summer drought conditions and high temperatures are the primary drivers of the inter-annual variability of fires [20]. Additionally, Gudmundsson et al. [21] showed that the probability of above-normal wildfire activity in southern Europe is significantly related to meteorological drought, despite the key role in wildfire dynamics of other factors (e.g., fuel availability). Focusing on the southern Mediterranean countries, recent analyses have shown an expected increase in the number of days of high fire risk, as well as an extension of the fire season and the size of burnt areas. In particular, Karali et al. [22] calculated the Canadian Fire Weather Index (CFWI) by using climate model simulations under the Intergovernamental Panel on Climate Change-IPCC, Special Reports on Emissions Scenarios-SRES, A1B scenario, and reported an increase of the fire risk over Greece in the near future. In particular, the authors reported an expected increase in the number of critical fire risk days in many Greek areas, by about 15-20 days in the near future (2021-2050), and by 
20-40 days in the distant (2071-2100) future. Similarly, for the area of NE Spain and the A1B scenario, Turco et al. [23] reported an expected positive trend in the number of fires in the near future (up to 2050) if no improvement of the currently adopted fire management strategies is assumed. Namely, the authors in their analysis of the current climate period 1970-2007 over Spain [20] have shown that the past improvement of the fire management has resulted in a negative trend of the number of fires, while the warming climate forcing alone would have led to a positive trend. However for the future conditions, further important improvements of fire management will be needed to counterbalance the climate trend towards warmer and drier summers that lead to more fires. The impact of climate change on wildland fire danger over Portugal has also been studied using dynamical downscaling between a general circulation and regional scale model [24]. The analysis has shown increase of CFWI values in the beginning of the summer season compared to the current climate. Moreover, the authors have reported a dramatic increase in the expected fire occurrence and burned area under climate change.

Applying appropriate Fire Danger Rating Systems (FDRS) is necessary, not only to alert the population regarding the emerging risks for wildfires, but also to assist the operational agencies and fire personnel in their planning activities and allocation of resources. It is worth mentioning that all the existing FDRS rate the risk for fire occurrence, fire spread, and difficulty for suppression. However, there is no rating available for the expected impacts on humans and ecosystems. Harris et al. [25] and Tedim et al. [26] emphasized the importance of developing such appropriate metrics, which will potentially enable the communication of intensity and impacts of wildfires in a similar way to those already used for other natural disasters or extreme events (e.g., Saffir-Simpson Scale for hurricane intensity, the Fujita scale for tornado intensity, etc.). Thus, by early communicating crucial information, i.e., the level of danger for fire spread, the physical properties of a wildfire (e.g., rate of spread, fireline intensity), and the potential impacts and protection measures, people may be assisted to protect their lives and their property. Taking into account the severity of impacts of wildfires on human life safety, the ecosystem, and the infrastructure, wildfire management strategies and policies are globally under continuous development. To this direction, emphasis is given to early warning and decision support systems supporting the needs of wildfire management agencies.

During the last two decades, in the U.S, a large number of decision support systems have been developed based on fire modeling algorithms such as: NEXUS [27], Fire and Fuels Extension to the Forest Vegetation Simulator (FFE-FVS) [28], Fire Area Simulator (FARSITE) [29], Fuel Management Analyst (FMA) Plus [30], FlamMap [31], and BehavePlus [32], as well as on geographic information systems such as: ArcFuels [33] and Wildland Fire Decision Support System (WFDSS) [34]. In particular, WFDSS is a web-based system providing access to weather information and forecasts, fire behavior predictions (including fire size probability), and to appropriate economic assessment tools. In Canada, the Canadian Forest Fire Behavior Prediction (FBP) System [35,36] has been developed as part of the Canadian Forest Fire Danger Rating System (CFFDRS), which also includes the extensively used in many other areas and countries Canadian Forest Fire Weather Index (FWI) [37]. The FBP System forms the basis of the Canadian wildland fire growth simulation model [38], named PROMETHEUS, that is similar to FARSITE. A relatively recent review of decision support systems (DSS) for prevention and suppression of wildfires is provided by Sakellariou et al. [39]. Namely, the authors have highlighted that several DSSs are fully integrated with GIS platforms, some are totally web-based including forest fire simulators and satellite technology tools, while others are constructed on database management systems and/or mathematical or economic algorithms for spatial optimization purposes. The extended review provided in [39] has highlighted the evolution of the DSSs worldwide, and the challenge related with the management of the specific natural disaster where the decisions should be taken in a short time frame.

Undoubtedly, in order to successfully address the challenges arising from wildfires, an integrated approach promoting, and subsequently being facilitated by, transnational collaboration is strongly required. The "Drought and fIre ObServatory and eArly waRning system-DISARM" project, which was financed by the European Union and the participating countries in the frame of the Interreg 
Balkan-Mediterranean initiative, brought together the countries of Greece, Bulgaria, and Cyprus, with an ultimate aim to establish a common strategic framework for tackling the challenges posed by wildfires. In the recent years, the three countries have already been facing such challenges. The aforementioned devastating wildfires of 2007 and 2018 in Greece resulted in 186 casualties. Bulgaria experienced significant increase of wildfires after 1990, with peaks in 1992, 1993,2000, and 2007, mostly caused by prolonged dry weather conditions. Cyprus suffered a recent (June 2016) deadly wildfire at Solea area in the Troodos Mountains, causing the death of two firefighters during their effort to tackle one of the largest wildfires in the recent history of the island.

The key purpose of the DISARM project was to develop, validate, and operationally apply a set of services that employ state-of-the-art observational and modeling techniques. It's ultimate aim was to assist the authorities in better preventing, addressing, and finally mitigating the adverse impacts of wildland fires, and also by taking note of their intensification due to climate change. In this context, the overall objective was to deliver an innovative, integrated observation and early warning system that may serve as a key tool for protecting the environment and, consequently, for promoting sustainable development in the vulnerable region of the southeast Mediterranean. This paper focuses on the presentation of the DISARM early warning system, with special emphasis given to particular innovations, the harmonization of methods and new pilot applications, as well as to the replication potential of the system. The following four sections present the four main pillars of the DISARM early warning system, while the last one is dedicated to conclusions and future prospects.

\section{DISARM Early Warning System}

\subsection{System Pillars}

DISARM uses state-of-the-art observational and modeling techniques in order to build a common prevention and mitigation framework for the vulnerable region of SE Mediterranean, integrated in a single platform: The "DISARM early warning system". This platform covers various time scales, ranging from the near real-time and extending to the short range, the monthly, and finally, the future timescale, encompassing the following four main pillars:

- $\quad$ Forecasting wildfire danger;

- remote sensing of wildfire activity;

- rapid response system for fire spread forecasting;

- climate change impacts on wildfire danger.

The first pillar of the DISARM early warning system provides fire weather forecasts within a forecast time-window of 3-4 days up to a month. The second pillar involves satellite remote sensing data in order to provide near real-time detection and monitoring of wildfires in the three partner countries. The third pillar was devoted to the development of a rapid-response fire spread forecasting system, aiming at supporting the operational firefighting activities of the Hellenic Fire Corps (HFC). It was given the name IRIS, after a messenger goddess of the Greek mythology. IRIS has been developed, adapted, tested, and operationally implemented in Greece, but it is highly replicable and could also be implemented in other countries as well, after the appropriate adaptation and testing procedures. Finally, the fourth pillar entails the development of a climatic component, which may provide assessments of fire danger and drought conditions over the study area for the next 30 years, based on state-of-the-art regional climate model simulations for two climate change scenarios.

\subsection{Data and Methods}

Weather and climate, both play a decisive role on wildfire occurrence and spread in many various ways. For instance, by contributing in the quantity and dryness of the vegetation that produces the necessary fuels, by igniting lightning strikes or by establishing favorable conditions for the fire spread. 
This is the reason why a large number of fire weather indices have been so far developed and are nowadays extensively applied. The most well-known indices used worldwide are the following:

- The Canadian Fire Weather Index (CFWI) was developed for Canada [37], and it is part of the Canadian Forest Fire Danger Rating System. CFWI is currently used worldwide, and takes into account the way that weather conditions affect the moisture content of different fuel layers;

- the Nesterov Index (plus the modified Nesterov Index) was developed for Russia [40], and according to the Hellenic Fire Corps (after personal communication), is quite representative for the Greek fire environment;

- the Fosberg Fire Weather Index (FFWI), developed for California [41];

- the McArthur Fire Danger Index (FDI), developed and widely used in Australia [42];

- the Angstrom Index (SAI), developed in Sweden in the 40's [43,44]; and

- the Haines Index [45], developed in the Northeastern United States.

Each one of the above-mentioned three collaborating countries has selected from the aforementioned fire weather indices, those which are mostly used by their end-users, and mainly their corresponding fire services. It should be noted that CFWI is a common index for all three countries.

Using data for the last decade, namely number of wildfires (including burnt areas) provided by the Fire Services of the participating countries and daily values of CFWI calculated from available meteorological data (mainly model derived re-analyses, detailed also in [11]), the CFWI thresholds for fire danger that are more appropriate to the fire environment of the three countries are being revisited. For the case of Bulgaria, a complex approach to fire danger assessment based on the use of fire weather indices considering the fuel dryness and the soil moisture deficit has also been explored. Details of the applied methodology are given in Section 3.

In order to provide monthly/seasonal forecasts of wildfire danger, the CFWI for the fire season period of May to October is calculated. In particular, we use the 6-hourly hindcast sub-daily reference climatology-available for the period 1982-2010-and the (raw) 6-hourly, 9-month lead time daily operational (single run) forecasts provided by Climate Forecast System version 2 (CFSv2) of the US NOAA National Centers for Environmental Predictions (NCEP). Despite the various sources of the model's uncertainties and the reduced confidence in the model skill for seasonal-scale numerical weather prediction, the challenges associated with such a seasonal fire danger forecasting are also being tackled under the first pillar.

The methodology adopted in the frame of the second pillar of DISARM encompasses the extensive use of remote sensing data. Namely, geostationary satellites, compared to polar orbiting satellites, do have the necessary high temporal resolution to practically achieve early detection. In particular, METEOSAT Second Generation (MSG) Spinning Enhanced Visible and Infrared Imager (SEVIRI), with a 5-min temporal resolution provided from the Rapid Scan Service, has been used for fire detection and monitoring. Namely data from the SEVIRI channels $4(3.9 \mu \mathrm{m})$ and $9(10.8 \mu \mathrm{m})$ are exploited for the calculation of various fire detection products as detailed in Section 4.

The third pillar, which is devoted to the development of IRIS rapid response system, a cornerstone of the project, is based on the combined use of:

- A state-of-the-art Numerical Weather Prediction (NWP) model (Weather Research and Forecasting WRF-ARW),

- an advanced two-dimensional fire spread model (SFIRE), and

- a prototype high-resolution geospatial dataset for the representation of fuels.

WRF-ARW and SFIRE are applied in a fully-coupled mode in order to encompasses the two-way interaction of forest fires with the local weather conditions. The architecture of IRIS, its operational deployment, and its evaluation during the 2019 fire season in Greece are presented in Section 5.

Finally, the fourth pillar is devoted to the assessment of fire danger and drought conditions for the future climate. For that purpose, state-of-the-art regional climate model simulations for two emission 
scenarios for the current (1971-2000) and the near future (2021-2050) periods are analyzed. Namely, the aforementioned regional climate model data are utilized for the calculation of the wildfire danger indices mentioned earlier (CFWI, FFWI, SAI), and for the calculation of the Standardized Precipitation Index (SPI) [46]. Details about the models and scenarios used are given in Section 6.

\section{Forecasting Wildfire Danger}

In this section, all the innovative aspects and challenges related to the forecasting of fire danger will be reported in detail. In particular, we will: (i) Discuss the representativeness of the CFWI thresholds utilized worldwide for the specific weather and climate conditions of each country participating in DISARM, (ii) assess the skill of a complex index developed for Bulgaria that accounts for the soil moisture deficit, and (iii) discuss the challenges related to monthly-scale forecasting of fire danger.

\subsection{Definition of Country Related Thresholds for Fire Danger}

A recent work by Papagiannaki et al. [47] pointed out that the thresholds adopted by the European Forest Fire Information System (EFFIS) for CFWI for the various levels of fire danger are too low for Greece. The authors, through statistical methodologies, proposed new thresholds that better meet the performance requirements. The CFWI thresholds for wildfire danger for the Greek territory were first developed using the calculated daily values of CFWI for the fire season (May-October), and fire data at municipal level over Greece for the period 2000-2016. For the computation of the CFWI, weather data were extracted from high-resolution regional climate simulations conducted with the WRF model (for the full model configuration see [48]). The analysis was limited to wildfires that burned more than 10 ha (2754 incidents in total). Fire Danger Categories (FDCs) were first defined by classifying wildfires based on the Fire Size (FS) of the burnt area. This is a common practice for mapping fire impact and defining thresholds for wildfire danger [49]. Following this practice, four FDCs were defined-for low (FS: 10-25 ha), moderate (FS: 25-100 ha), high (FS: 100-400 ha), and very high danger (FS: $>400 \mathrm{ha}$ ).

In the same work, in order to establish the relationship between the CFWI and the level of wildfire danger in terms of the area likely to be burned (FS), two statistical methods were applied (cluster and non-linear regression analysis). Finally, 4 sets of FWI thresholds that met specific conditions were identified, and they were also compared to the corresponding EFFIS CFWI thresholds (Figure 1). To evaluate the performance of the various sets of CFWI thresholds against the original classification of wildfires according to FS, multi-category $(4 \times 4)$ contingency tables were formed, and a set of verification scores were calculated: Proportion Correct (PC), False Alarm Ratio (FAR), and distributions related to estimation errors (off-diagonal frequencies of the contingency tables) of specific nature (overestimation or underestimation). The results showed that the proposed CFWI thresholds were capable of: (i) Increasing the overall accuracy by a factor of 1.9-2.6, (ii) reducing the excessive overestimation of wildfire danger associated with the EFFIS ones, and (iii) significantly increasing the reliability regarding the danger classification. The full methodology and results can be found in [47].

Subsequently, in order to assess the predictive ability of the proposed FWI thresholds for wildfire danger, we applied it in the other 2 partner countries as well (Cyprus and Bulgaria). As in the case of Greece, only wildfires that burned forests, shrubland areas, and grasslands were taken into consideration.

Data for Cyprus were provided from the Cyprus Forestry Department and include all the wildfires cases of the 2007-2016 fire seasons (May-October) that burned more than 10 ha (147,665 ha burnt in total). The respective Bulgarian sample includes all the wildfires that occurred in July and August 2016 and burned more than 10 ha (16,555 ha burnt in total). Table 1 presents descriptive statistics for FS and the respective CFWI data series for the 2 samples. The number of observations $(\mathrm{N})$ refers to the amount of wildfire daily events occurred in each country. The FS thresholds for classifying the FDCs (Fire Danger Categories) in Greece were adjusted to account for the Cyprus and Bulgarian samples, so that the frequency distribution to the FS classes does not change. 


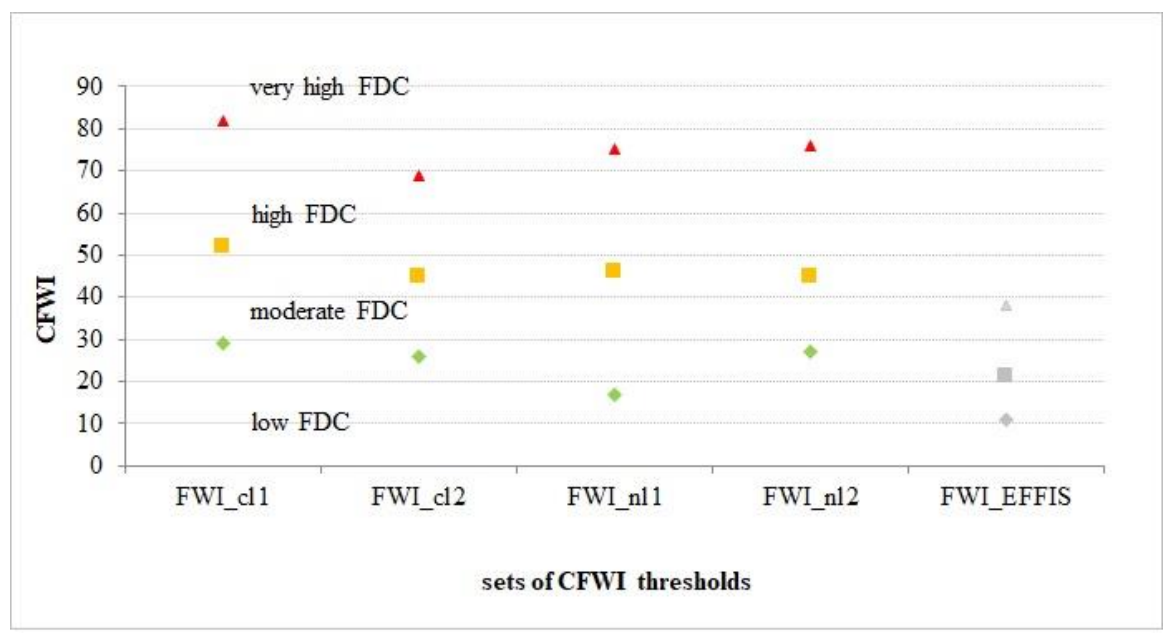

Figure 1. Sets of Canadian Fire Weather Index (CFWI) thresholds for wildfire danger in Greece, as resulted from the statistical analyses: k-mean (FWI_cl1) and k-medians (FWI_cl2) cluster analysis, exponential (FWI_nl1) and power nonlinear (FWI_nl2) regression models. The European Forest Fire Information System (EFFIS) FWI thresholds for Europe are included for comparison. The Fire Danger Categories (FDCs) defined by the thresholds are also depicted.

Table 1. Descriptive statistics for fire size (FS) and the respective FWI data series for the Cyprus and Bulgarian samples.

\begin{tabular}{ccccccc}
\hline Dataset & Variable & N & Mean & Std. Dev. & Min & Max \\
\hline Cyprus sample & FS & 607 & 243 ha & 236 ha & 11 ha & 1886 ha \\
& FWI & 607 & 43.9 & 15.4 & 2.0 & 95.8 \\
\hline Bulgarian sample & FS & 71 & 233 ha & 582 ha & 11 ha & 4500 ha \\
& FWI & 71 & 24.5 & 14.4 & 1.9 & 56.0 \\
\hline
\end{tabular}

A first overview of the CFWI values suggests that the EFFIS thresholds overestimate danger for Cyprus (Figure 2). Over 65\% of the CFWI observations are attributed to the 'very high' FDC by the EFFIS thresholds, while wildfires of 'low' to 'medium' danger account for less than $10 \%$. Conversely, most of the sets of CFWI thresholds that were found suitable for Greece appear to omit the 'very high' FDC. The only exception is the FWI_cl2 that shows a more balanced distribution of the CFWI values across the FDCs. In the case of Bulgaria, the EFFIS CFWI thresholds are also associated with a high percentage of very high danger assessment, while the ones proposed for Greece omit this FDC as well.
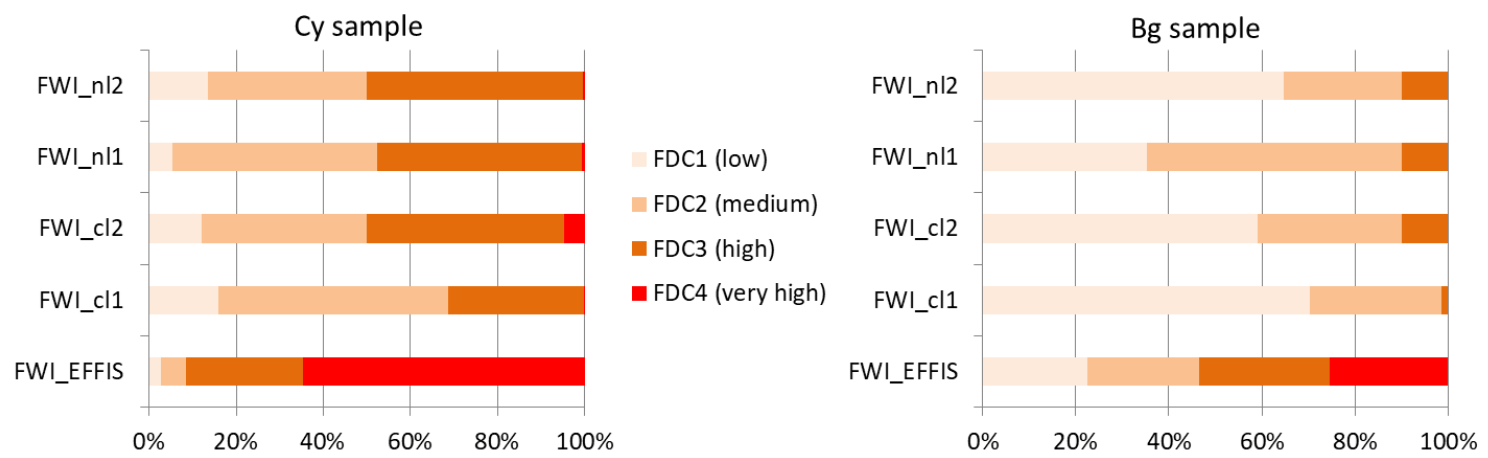

Figure 2. Distribution (\%) of CFWI values for each set of the examined CFWI thresholds for the Cyprus (Cy) and Bulgarian (Bg) sample across the FDCs.

The assessment of the CFWI thresholds' performance should take into account the capability of the thresholds to classify the wildfire danger at the four levels of FDC. Otherwise their applicability 
is questionable, as they may not provide alerts for all levels of danger. Therefore, for Cyprus, the verification of wildfire danger predictive performance can apply only to FWI_cl2, FWI_nl1, and FWI_EFFIS. Concerning Bulgaria, only the EFFIS thresholds can be evaluated, although the sample size is relatively low to provide reliable results. Table 2 presents the verification scores for the performance of the examined sets of FWI thresholds over Cyprus and Bulgaria.

Table 2. Verification of EFFIS and model-derived sets of CFWI thresholds over the Cyprus and Bulgarian samples. Contingency tables were used for the assessment.

\begin{tabular}{|c|c|c|c|c|c|c|}
\hline $\begin{array}{l}\text { Set of FWI } \\
\text { Thresholds }\end{array}$ & & PC (1-FAR) & $\begin{array}{l}\text { Under-Estimation } \\
(\%)\end{array}$ & $\begin{array}{l}\text { Over- Estimation } \\
(\%)\end{array}$ & $\begin{array}{c}\text { Underestimated } \\
\text { Events Closest to } \\
\text { True FDC(\%) }\end{array}$ & $\begin{array}{l}\text { Misses Closest to } \\
\text { True FDC (\%) }\end{array}$ \\
\hline FWI_cl2 & Cy & 0.22 & 13 & 66 & 70 & 56 \\
\hline FWI_nl1 & Cy & 0.20 & 12 & 69 & 70 & 60 \\
\hline FWI_EFFIS & Cy & 0.08 & 04 & 88 & 75 & 23 \\
\hline FWI_EFFIS & $\mathrm{Bg}$ & 0.28 & 11 & 61 & 75 & 51 \\
\hline
\end{tabular}

The scores show that in the case of Cyprus, the CFWI thresholds developed for Greece perform better than the EFFIS ones with respect to the PC and the share of total overestimated events. Furthermore, the EFFIS CFWI thresholds result in a much lower fraction of the missed events that are classified as the 'closest to the true' FDC (23\%). Practically, this means that most of the missed events are underestimated or overestimated by more than 1 danger level. In the case of Bulgaria, the EFFIS thresholds are relatively satisfactory, even if there is a high share of overestimation (61\%) and of missed events that deviate significantly from the actual FDC.

Overall, the above results indicate that the EFFIS thresholds are not suitable for Cyprus, while they can be considered suitable for Bulgaria, although a larger sample is required to reach safer conclusions. The CFWI thresholds developed for Greece may improve the wildfire danger predictability for Cyprus, however, not to an acceptable extent. The results highlight the vital role each country's fire environment plays on the extent of a fire, especially when combined with critical weather conditions. In addition, climatic differences can partially explain why CFWI thresholds suitable for Greece are shown to be very high for colder and wetter areas, such as Bulgaria. The main conclusion of the above analysis is that the critical values of the fire weather indices have to be properly adapted so that the specific conditions of each area affecting the relationship between the index and the fire size are also taken into account.

\subsection{Assessment of a Fire Danger Index Accounting Soil Moisture Deficit}

The moisture content of living and dead plants (fuels) has an overwhelming importance pertaining to the possibility and properties of ignition and spread of wildfires [50]. Although several factors need to be considered for a comprehensive evaluation of fire danger [51], most operational danger indices rely almost exclusively on meteorological data because they are relatively easy to obtain and provide a good prediction of Fuel Moisture Content (FMC) status [37,52]. The National Institute of Meteorology and Hydrology (NIMH) of Bulgaria has been working on the development of a complex approach for fire danger assessment in the frame of several projects [53-55].

To account for the live fuel dryness and for the assessment of fire susceptibility of vegetation cover for the region of Bulgaria, NIMH has developed the Soil Moisture Deficit (SMD) Index of Fire Danger (SMDIFD). This index is based on Soil Moisture (SM) modeling by a simple 2-layers 'SVAT_bg' model [56] and a subsequent scaling of SMD towards fuel dryness approximating fire danger with a 5-level scale. For diagnoses, calculations are performed at a site scale using NIMH synoptic network observations (Figure 3a) while for forecasting purposes, the European Centre for Medium-Range Weather Forecasts (ECMWF) NWP model data are used. SMDIFD is generally based on the following physical definitions: 
- Fire danger rating is approximated by vegetation-soil system dryness, SMD along the root zone depth;

- $\quad \mathrm{SMD}$ results from the misbalance between the moisture input by Precipitations $(\mathrm{P})$ and moisture loss by evapotranspiration (AET);

- SMD (severity, duration) provides an estimate of the live vegetated fuel moisture-flammability and background for SMDIFD;

- scaling of SMD to designate dry vegetated surface susceptibility to fire ignition and spread, by a 6-level quantitative index. Classes of fire danger are defined according to the SMD as its' thresholds are selected based on the specific soil-hydrophysical properties for the region;

- along this principle, accounting for vegetation as a dynamic component of the climate system, the P-AET relations, and fire occurrence (ground observations of actual fires) - the fire danger classes are defined, and maps for fire danger are daily produced (Figure 3a);

- SMDIFD has been developed for two types of land cover: Grassland and wheat field.

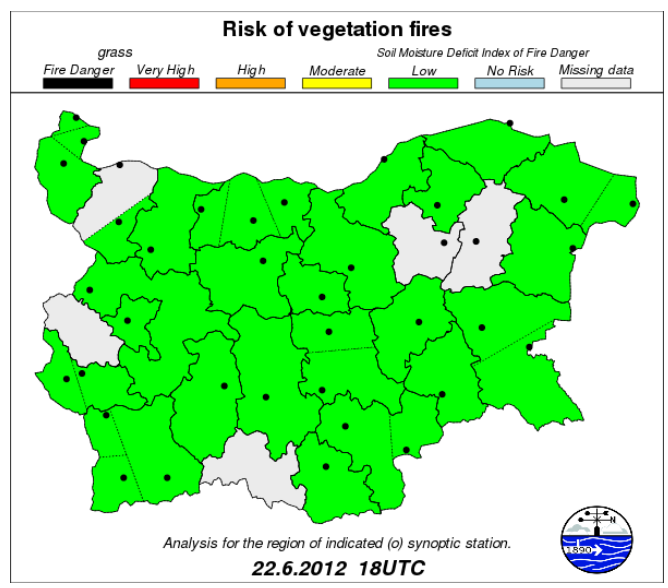

(a)

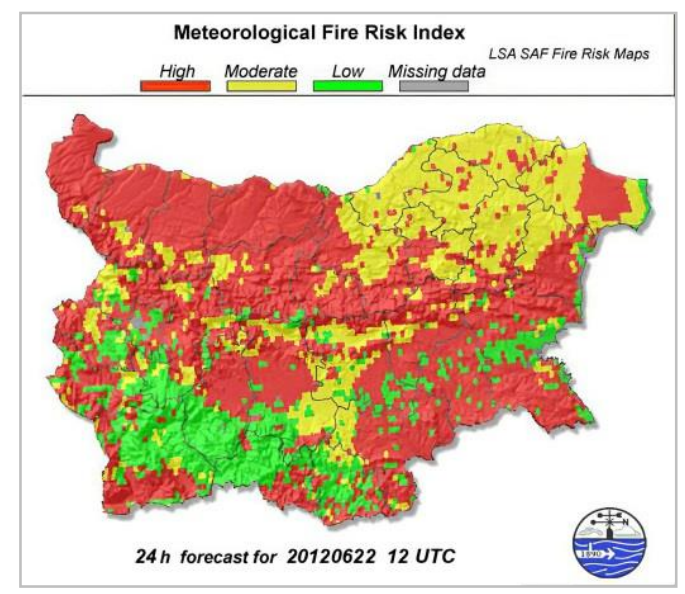

(b)

Figure 3. (a) Map of Soil Moisture Deficit Index of Fire Danger (SMDIFD) from measurements of SYNOP stations, and (b) Meteorological fire danger according to Satellite Application Facility on Land Surface Analysis (LSA-SAF) Fire Risk Map (FRM) product, both valid for 22 June 2012 [54].

Since 2012, NIMH also uses the meteorological FDI based on CFWI adaptation in the fame of Satellite Application Facility on Land Surface Analysis (LSA-SAF) [57]. Daily forecasts based on the LSA-SAF Fire Risk Map (FRM) product are provided as layers with 3 classes (low, moderate, high) with a spatial resolution of about $5 \mathrm{~km}$ (Figure $3 \mathrm{~b}$ ). The FRM product from the LSA-SAF combines information from ECMWF model output and vegetation state from the SEVIRI instrument of METEOSAT. Recently, LSA-SAF adopted a 5-level scale FDI over the Mediterranean Europe [58], which is still in a pre-operational phase. NIMH's long-term experience in the operational use of the FRM product indicates that it often overestimates the fire danger over Bulgaria in spring when the land cover and live fuel are moist, especially during heat wave episodes as well as in strong wind conditions. Additionally, the FRM product may underestimate fire danger during late autumn, when the air temperature is not very high, but the living fuel is dry [59]. Therefore, during hot days, a high level of meteorological fire danger can be present at a wide range of land surface state conditions.

The 24-h forecast of LSA-SAF FRM valid for 22 June 2012 in a 3-level scale (Figure 3b) is compared with SMDIFD 6-level scale (low, moderate, high, very high, extreme, no risk) analyses on the same day (Figure 3a). During the heat wave episode in June 2012, three days with daily temperature records were detected in Bulgaria. Meteorological fire danger according to the FRM product is estimated as 'high' due to extreme weather conditions. On the contrary, the vegetation-soil system across Bulgaria appears moist enough, and thus the SMDIFD indicates 'low' fire danger (Figure 3a). A better understanding 
of FMC and fire occurrence relations is decisive, and a main question is how to account for drought impacts, i.e., of the life fuel dryness into fire danger for the purposes of its diagnoses and early warning.

To approach the predictability of wildfires, we rely on results showing that large-scale droughts significantly affect continental scale wildfire activity (e.g., [60]). This, combined with the finding that drought impacts on Mediterranean fire-prone regimes have recently increased [61], suggests that for wildfire activity in Southern Europe, drought should be taken into account. To this direction, NIMH developed a Complex Fire Danger Index that combines meteorological fire danger according to LSA-SAF FRM and land surface state according to SMDIFD in a common framework [54,59] (Complex Index). This approach, which was promoted in the framework of DISARM project for Bulgaria, provides warnings in a 3-level scale.

In the frame of the LSA-SAF Consortium, NIMH works on the evaluation of the behavior of meteorological products, including those related to fire danger for the region of East Mediterranean (Bulgaria). In the frame of EUMETSAT LSA-SAF CDOP-3 Project [53], the behavior of available fire danger indices was evaluated through an elaborated Quality Monitoring $(Q M)$ procedure. Some aspects on the obtained results [53] are briefly presented here. For this study, the performance of the available FDI's for the operational environment of NIMH are used in a comparative analysis in real fire situations and in a non-risky environment. The indices that will be commented in this context are the new version of the meteorological FDI, the SMDIFD characterizing life fuel dryness, and their complex consideration. For a better reflection of environmental constrains, we developed a new complex index combining meteorological fire danger (characterized by the FDI) and risk provoked by terrestrial drought and live fuel dryness. This is a new 5-level scale index introduced as the "Complex New Index-CNI". The period of study spans from June to August, of the years 2016 and 2017. The forest fire activity in Bulgaria in those two consecutive years was higher than average in 2016 and lower than average in 2017. The evaluation procedure is generally based on qualitative and quantitative comparisons between indices towards reference data. The records of ground based observations of actual fires in forest and shrubs/grass vegetation areas have been provided by the State Forest Agency of Bulgaria (for fires occurrence) and the Fire Safety and Civil Protection Directorate, Ministry of Inner Affairs.

The qualitative comparison between the indices shows that the FDI and the CNI vary considerably (Figure 4). In particular, for 2016, while CNI seems to follow the behavior of the fire activity, SMDIFD shows reverse behavior (decreases with increasing fire activity). The FDI does not strictly follow the fire activity, i.e., there are similar high levels of fire danger for June and August, whereas the number of fires varies significantly. For 2017, the CNI (SMDIFD) shows an increasing (decreasing) trend with increasing fire activity, while FDI is almost constant with a slight decrease though observed at the end of August. Summarizing, for the tested period, CNI shows better skill than the FDI.

To account for the sensitivity of fire danger classes, contingency tables have been produced. The tables show simultaneously the level of fire danger according to the different indices and the number of detected ground fires (respectively \% of all cases with corresponding level of fire danger). The comparison between the FDI and the complex product FDI-SMDIFD denotes the importance of live fuel dryness for the region of Easter Mediterranean (Bulgaria). In particular, both indices express relevant distribution of fire occurrence according to the fire danger class (in a scale from green to red). The increase of fire danger class corresponds to increase of 'Yes' cases; the CNI produces fewer false alarms at low probability (green/yellow codes) of fire occurrence. At high levels of fire danger (red/dark red) in 2016, the year of higher forest fire activity, the two indices exhibit very similar behavior concerning fire occurrence. Under these circumstances, both meteorological fire danger and live fuel dryness favor fire occurrence. However, for 2017, the year of lower wildfire activity, the complex FDI-SMDIFD exhibits a better skill than FDI. 
Smoothed Averaged parameters

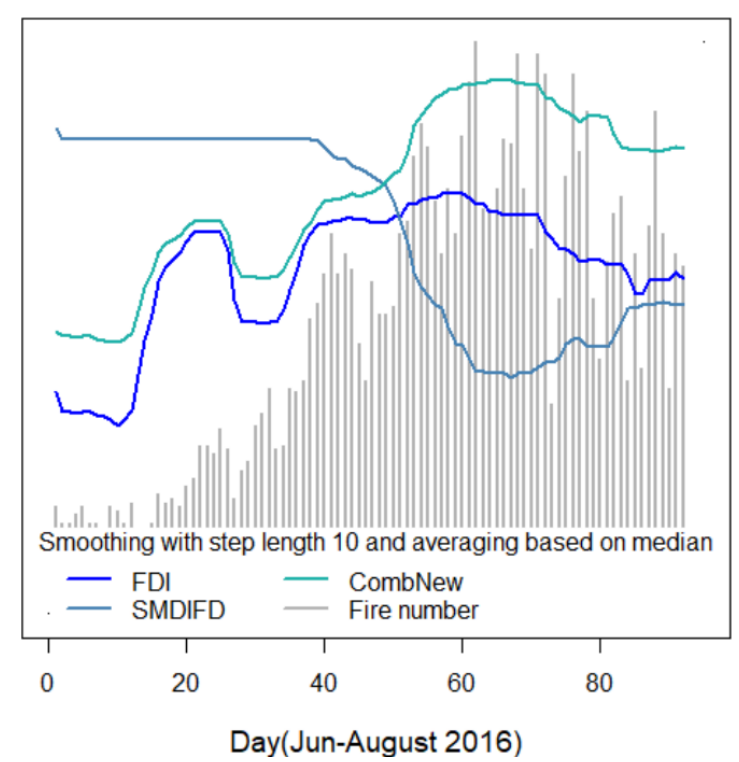

(a)
Smoothed Averaged parameters

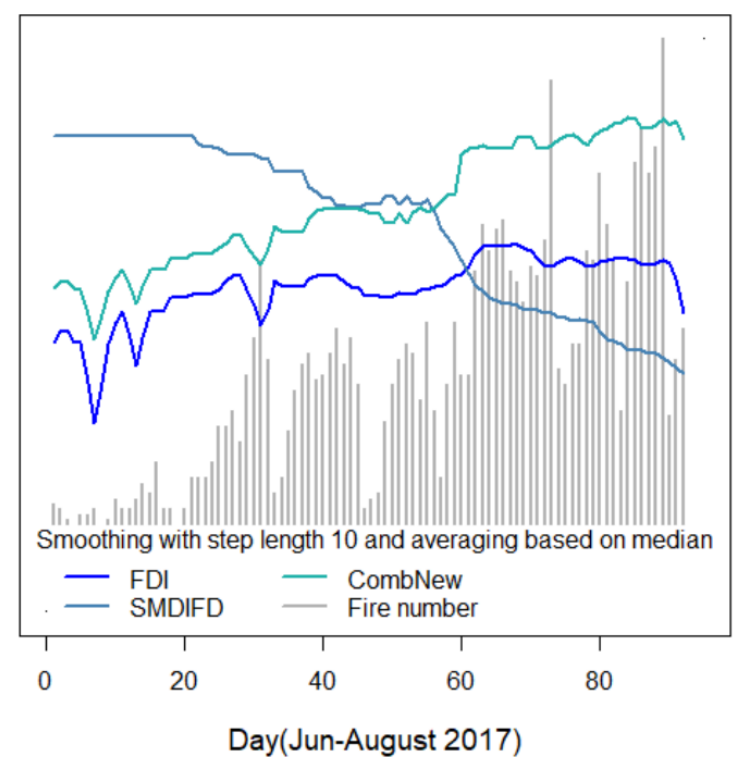

(b)

Figure 4. Smoothed averaged course of Fire Danger Index (FDI), Soil Moisture Deficit Index of Fire Danger (SMDIFD), and Complex New Index (CNI) along with fire activity (grey bars) June-August of: (a) 2016 and (b) 2017.

By applying a logistic regression technique, the evaluation of the relation of those indices indicating the probability of fire danger/occurrence and the number of actual fires, is possible. The evaluation proves that CNI shows better model behavior, thus underlining the role of accounting for the live fuel dryness in arid regions like Eastern Mediterranean [53]. In Bulgaria, some of these products are currently used for providing meteorological services for national authorities dealing with fire prevention. The reported results are promising and may be used for further improving early warnings at a national/regional level.

\subsection{Challenges for Seasonal Prediction of Fire Danger}

Despite the various sources of model uncertainties involved and the reduced confidence in model skill over some regions [62], long-term numerical weather forecasts that generate a wealth of physical parameters (e.g., temperature, precipitation, wind, etc.) with sub-daily frequency may be employed to provide early warning for extreme high-impact meteorological events. Hence, the consideration of long-term numerical weather output could potentially serve as a valuable tool for the assessment of potential weather-induced drought and fire hazard, since they provide a broad outlook of relevant meteorological variables up to several months ahead. Seasonal forecast outputs, after appropriate calibration, can be implemented in a forecast-based drought and wildfire hazard monitoring system. Therefore, seasonal forecasts can serve as useful tools to enhance the preparedness levels of forest fire service agencies and inform wildfire management decision-makers to better plan and adapt their wildfire prevention measures well in advance (i.e., before the onset of fire seasons).

To demonstrate seasonal wildfire outlook for the Balkan and East Mediterranean area, in the context of the DISARM project, the CFWI for the fire season period of May to October (hereafter, MJJASO) is calculated. For this purpose, we use long-term simulation data from the Climate Forecast System version 2 (CFSv2) of the US NOAA National Centers for Environmental Predictions (NCEP) [63]. In particular, we use the 6-hourly CFSv2 hindcast sub-daily reference climatology-available for the period 1982-2010 - and the (raw) 6-hourly, 9-month lead time daily operational (single run) forecasts. The global atmospheric component of CFSv2 employs a spectral resolution of T126, corresponding to a 
spatial horizontal resolution of about $0.937 \mathrm{o}$ (approx. $100 \mathrm{~km}$ along the Equator). In our calculations of the CFWI, we employ two fire danger classification schemes. The first is based on the European Forest Fire Information System (EFFIS), which is harmonized over Europe, and the second (GR-NOA) was introduced by Papagiannaki et al. [47] and is discussed in Section 3.1. Among the devised classifications presented in Section 3.1, we use the FWI_nl1 set. Although in Section 3.1 we focus on the investigation of four fire danger categories, here we do present five categories including the 'very low' one in order not only to facilitate a fair comparison to the standard EFFIS fire danger classification scale, but also to take into account any implications that might have been introduced by the coarse spatial resolution of the CFSv2 dataset.

In our analysis of the CFWI predictions, using raw daily output from the CFSv2, we do not apply the methodology of seasonal probabilistic forecast, in combination with a reference (validation) climatology [64] or any other spatial downscaling and bias correction approach [65]; the use of these approaches is beyond the scope of this work. What we adopt is an exploratory methodology similar to the one used at the US CEFA Desert Research Institute (https://cefa.dri.edu/CFS/fwi.php).

The monthly-averaged outlooks of the CFWI for both fire danger classification scales are depicted in Figure 5. Based on the EFFIS classification (Figure $5 a-c$ ), the spatial patterns of the CFWI warning levels for most parts of Greece and Bulgaria are almost unchanged between June and July, except for Attica and the Aegean islands, where the fire danger is elevated from 'Low' in June to 'Moderate' in July. The latter also describes the situation for Cyprus. According to the rating scheme introduced over Greece and presented in Section 3.1 and in [47], GR-NOA hereafter, (Figure 5d-f), the level of fire danger is overall lower than the corresponding EFFIS classification for all three months. On average, over the domain of interest, August is the month where the CFWI reaches its peak danger level for both classification regimes. However, in several parts of the domain, the CFWI fire danger might be under- or overestimated by both schemes. This shortcoming may be (partially) explained by a possible deficiency of the CFSv2 model, especially regarding the prediction of precipitation and wind patterns over the DISARM domain. This might be attributed to the coarse spatial resolution of the model data where the features of the topographically complex terrain and coastal areas might not be sufficiently resolved in the global CFSv2 model simulations.

Using the CFSv2 hindcast daily climatology (1982-2010), the estimated (mean) CFWI seasonal anomaly for the considered fire season (MJJASO, 2019) is presented in Figure 6a. Likewise, Figure 6b-d show the monthly (averaged) anomaly for the months of June to August of 2019. Throughout the region of interest, the dominant spatial pattern corresponds to a negative anomaly in the values of the CFWI. Some areas over the Northwest Balkans show slightly positive values compared to the reference model climatology for the month of June.

Below we cluster the fire danger classes of the CFWI, for both EFFIS and GR-NOA schemes, into broader categories. More specifically, the 'high' and 'very high' fire danger categories from now on will be considered as one and will be named as 'high' danger. Figure 7 depicts the number of days in the 'moderate' and 'high' categories for the entire fire season of 2019 (MJJASO), based on the operational CFSv2 long-term outlook dataset. The EFFIS classification yields a rather uniform spatial distribution, for the number of days falling into the 'moderate' CFWI fire danger level, up to about 40 days (Figure 7a). Instead, the GR-NOA classification predicts a higher number of days in this category for the southeastern regions of the domain, while for the northwest Balkan, the prediction remains roughly under 20 days (Figure 7b). On a national level, the average number of days predicted by the EFFIS (GR-NOA) scheme for (a) Greece is 52 (62), (b) Cyprus is 58 (126), and (c) Bulgaria is 26 (19). While for Greece and Cyprus with the EFFIS scheme we obtain a higher number of days compared to the GR-NOA scheme, the opposite occurs for Bulgaria. This finding is in accordance with the one in Section 3.1, showing that the EFFIS thresholds overestimate the fire danger over Greece and Cyprus. Thus the GR-NOA thresholds are more representative of the specific country characteristics, while for Bulgaria it seems that the EFFIS thresholds are more suitable. 


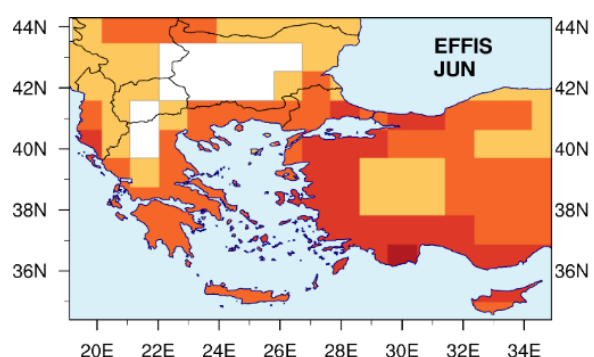

(a)

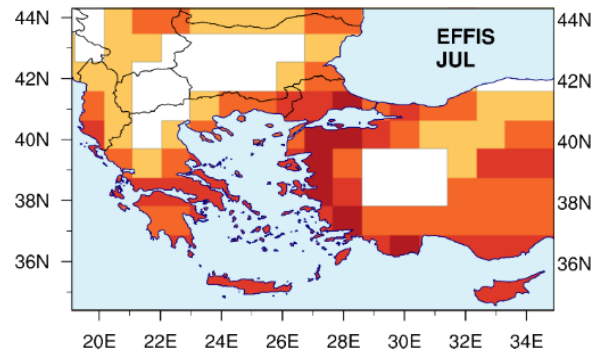

(b)

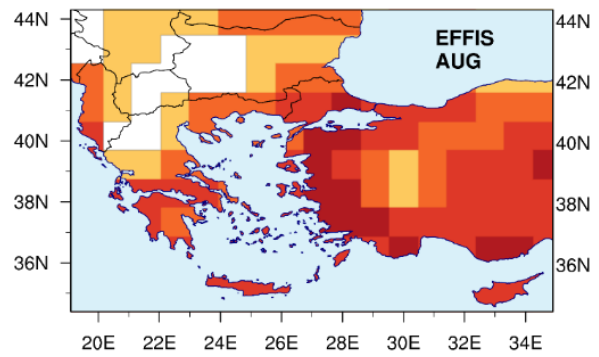

(c)

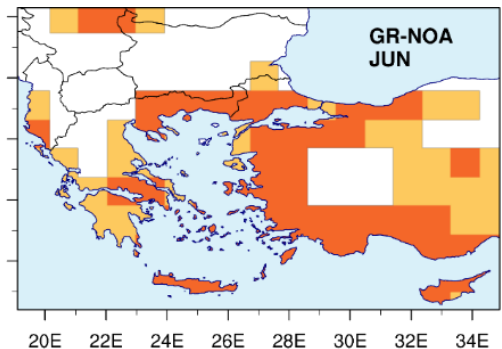

(d)

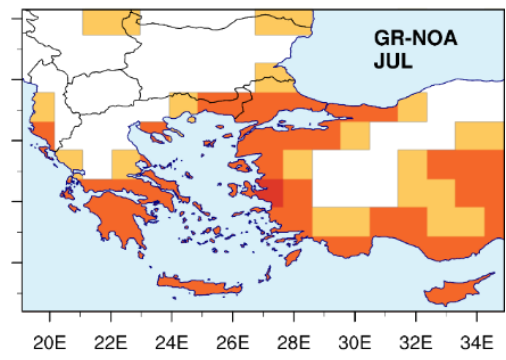

(e)

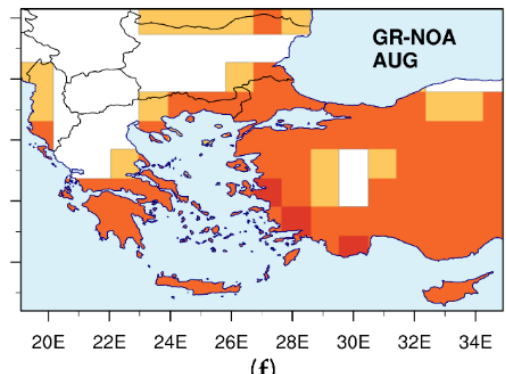

(f)

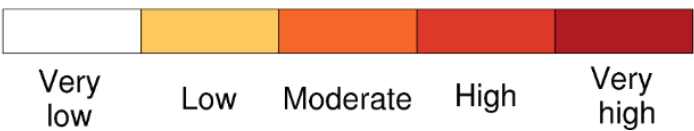

Figure 5. $(\mathbf{a}-\mathbf{c})$ EFFIS and (d-f) GR-NOA fire danger classification scales: Monthly mean outlook of the CFWI spatial distribution, over the DISARM (Drought and fIre ObServatory and eArly waRning system) domain, for the summer months June (top), July (middle), and August (bottom row) of 2019.

Similarly, the EFFIS scheme counts a very low number of days in the 'High' CFWI risk level category for the northwestern Balkans and central-towards northeastern parts of Turkey. This number significantly increases for the Greek islands in the southeastern Aegean Sea as well as Cyprus (Figure 7c). On the contrary, the GR-NOA classification shows a rather uniform pattern over the entire DISARM domain, with the number of estimated days is ranging around 10 (Figure $7 \mathrm{~d}$ ). The average predicted number of days, within the 'high' CFWI danger class, according to the EFFIS (GR-NOA) scheme for (a) Greece is $~ 54$ (7), (b) Cyprus is 110 (3), and (c) Bulgaria is 16 (3).

Finally, based on the aforementioned aggregated CFWI fire danger classes, we determined the change in the number of days in each category for the summer months of June, July, and August of 2019 compared to the corresponding CFWI mean values as derived from the CFSv2 hindcast daily climatology (1982-2010). For the three collaborating countries of the DISARM project, the average estimated change in the number of days, compared to the computed CFWI hindcast daily climatology, within the 'high' CFWI fire danger range, according to the EFFIS (GR-NOA) scheme for the month of June 2019 is: For Greece approximately -3 (0), for Cyprus -7 (-2), and for Bulgaria 1 (0). Similarly, regarding the month of July (2019), the number of days within the 'high' category for Greece is -9 $(-1)$, for Cyprus 1 ( -3$)$, and for Bulgaria -9 (0). For August 2019, for Greece it is $\sim-7(-1)$, for Cyprus $0(-2)$, and for Bulgaria $-8(0)$. Even if a slight overall tendency for a decrease based on the EFFIS scheme is noticed, however, we cannot draw any statistically significant conclusion at this stage. 


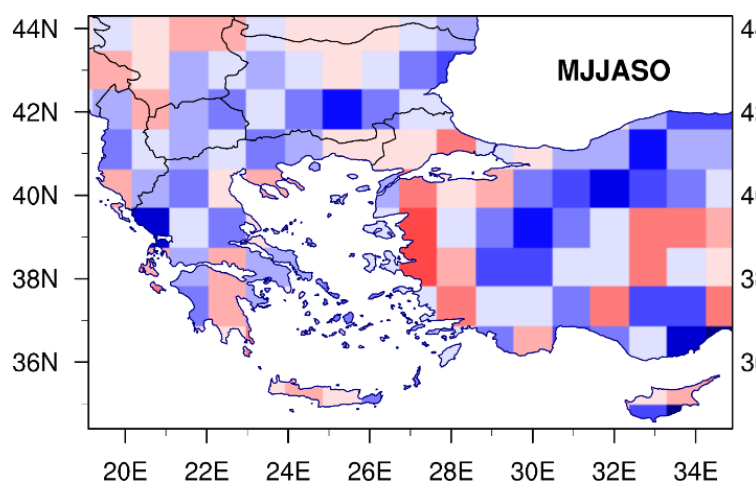

(a)

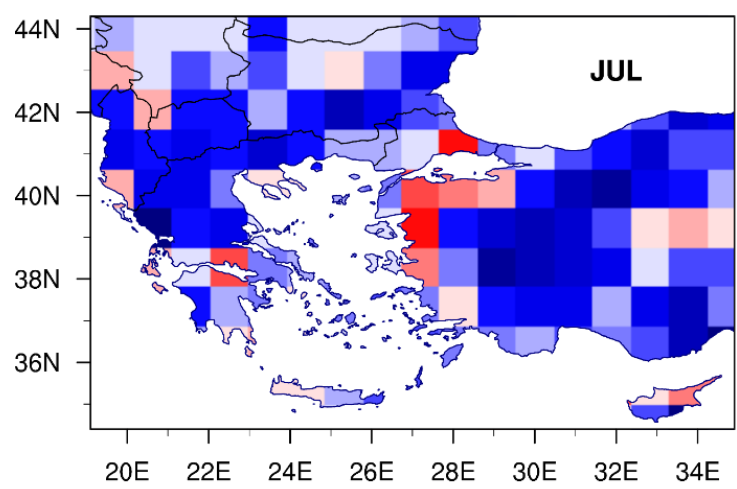

(c)

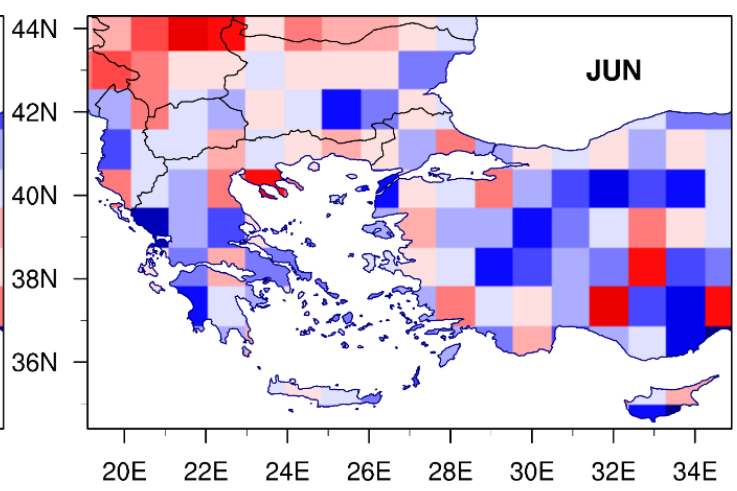

(b)

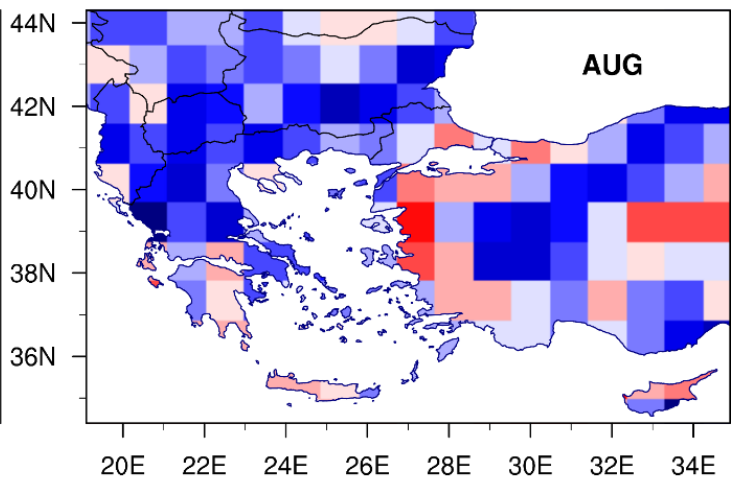

(d)

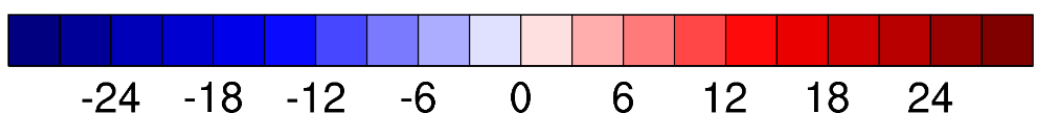

Figure 6. (a) CFWI (mean) anomaly of the 2019 fire season MJJASO with respect to the mean CFWI of the model climatological reference period 1982-2010. The CFWI (mean) anomaly for (b) June, (c) July, and (d) August 2019 with respect to the derived CFWI daily climatology for the period 1982-2010.

The results of our explanatory analysis of the long-term CFWI fire danger warnings, according to both EFFIS and GR-NOA fire danger rating schemes, corroborate that the fire danger classes have to be judiciously selected and calibrated. This should be based on the relevant morphological forest characteristics, vegetation type, and fire occurrence data at individual country and local scales (shown in Section 3.1). In addition, general circulation models configured to produce seasonal operational weather forecasts such as the CFSv2, are still restricted by their coarse horizontal resolution and their limited ability to accurately resolve physical processes (e.g., convection) taking place at sub-grid scales. This may lead to less skillful predictions of precipitation, wind patterns, and temperature, essential input variables in weather-induced drought and wildfire danger indices. Hence, to adequately address the above issues, it is important to leverage our efforts to improve the reliability of the seasonal CFWI predictions, derived from the raw CFSv2 meteorological input, by following a more systematic investigation.

One procedure that may potentially improve the accuracy of the raw CFSv2 seasonal forecasts, before being applied in the calculation of the CFWI, is the use of dynamical downscaling. Namely, all available ensemble members of the long-term CFSv2 forecasts could be employed, as forcing input fields, to conduct dynamical downscaling simulations at finer spatial scales, using a regional climate model [66]. However, this is a highly demanding computational task. A less computationally expensive technique, and often used in climate change impact studies, that might help reduce the ensemble spread of the CFSv2 output, is the statistical downscaling followed by bias correction $[67,68]$. 
The spatially downscaled results can then be used along with a probabilistic approach to enhance the validity of the long-term, seasonal wildfire danger predictions [64].

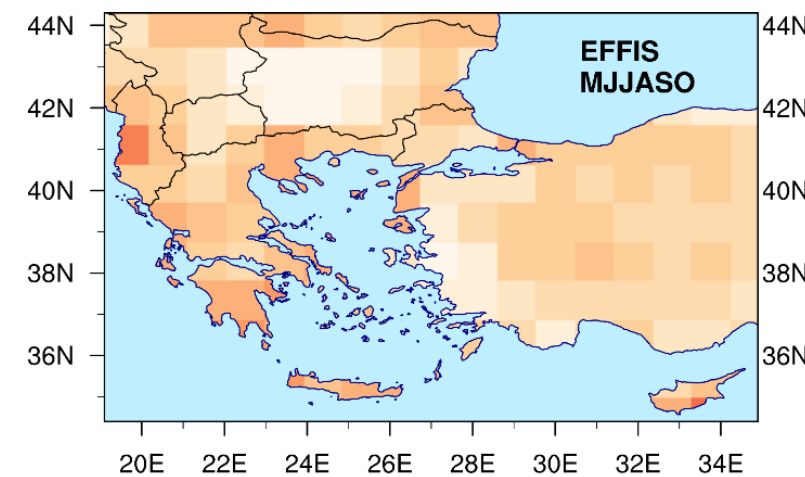

(a)

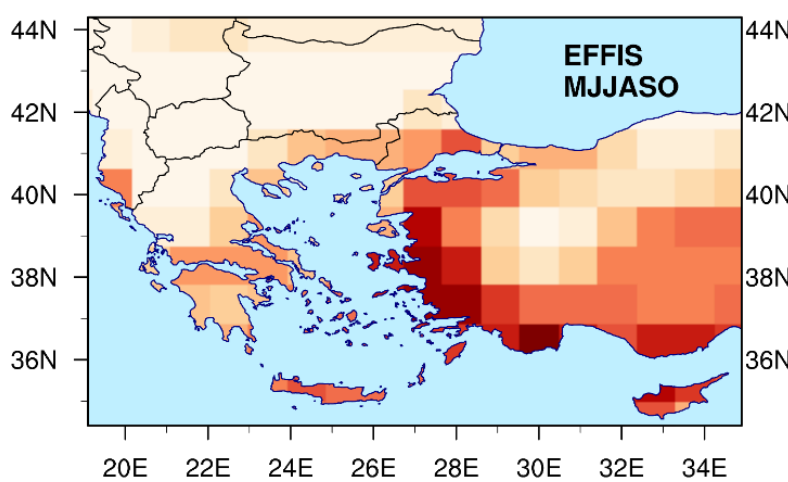

(c)

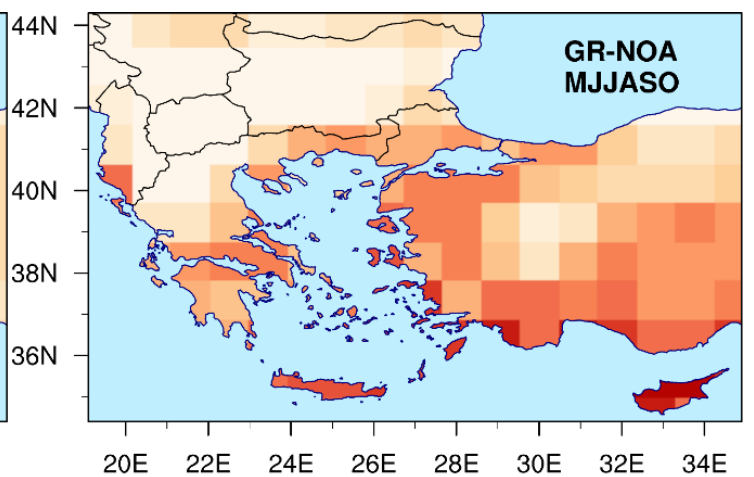

(b)

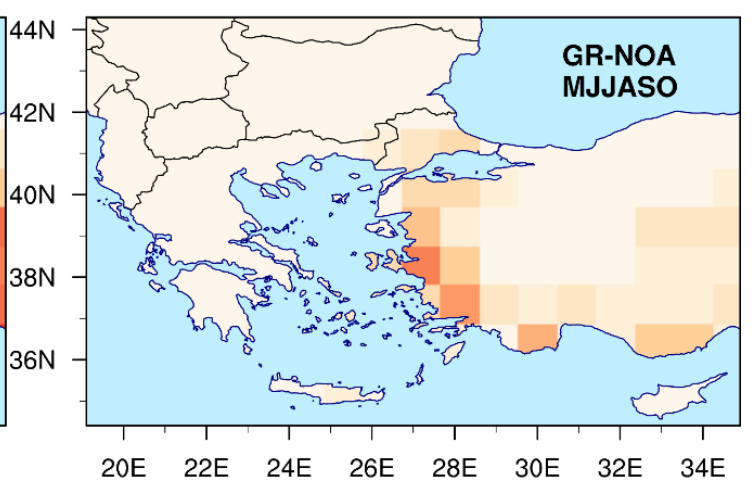

(d)

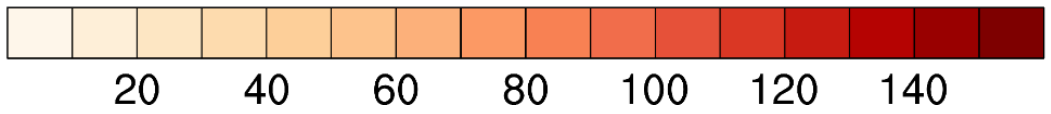

Figure 7. (a) EFFIS and (b) GR-NOA fire danger classification scales: Mean number of days within the moderate CFWI risk level over the 2019 fire season (MJJASO). (c) as in (a), and (d) as in (b), but for high CFWI risk.

\section{Remote Sensing of Wildfire Activity}

A major goal of the DISARM project was the near-real time detection and monitoring of fire events in all partner countries by using MSG SEVIRI data. Special attention was given to the early detection of wildfires in the Eastern Mediterranean region so as to reduce losses in natural ecosystems and in socio-economic systems. During active wildfires, the thermal signal is discrete, especially when instruments that do not saturate at low temperature are being used.

For the purposes of the project, MSG SEVIRI data were considered suitable since they are generated every 5 and $15 \mathrm{~min}$, thus fulfilling the critical precondition of high temporal resolution. Furthermore, the European Organization for the Exploitation of Meteorological Satellites (EUMETSAT) as well as the EUMETSAT LSA-SAF, provide several fire products based on MSG data that can be used for detection and monitoring of wildfires. Such products are the Rapid Scan Active Fire Monitoring (FIR) [69], the Fire Radiative Power (FRP) ([57,70]), and the Fire Detection and Monitoring (FD\&M) ([57,71]).

FIR is a fire detection product indicating the presence of fire within a pixel. It is based on a threshold technique, using SEVIRI channels $4(3.9 \mu \mathrm{m})$ and $9(10.8 \mu \mathrm{m})$. The algorithm is applied for all land surface pixels, excluding bare soil surface pixels and coastal pixels. The underlying concept of the algorithm takes advantage of the fact that SEVIRI channel IR3.9 is very sensitive to hot spots, which are caused by fires. FD\&M is based on the algorithm FIDALGO (Fire Detection Algorithm) developed within the LSA-SAF [72] to identify SEVIRI/METEOSAT pixels potentially contaminated 
by fires. Finally, the FRP product takes advantage of the temporal resolution of SEVIRI and relies on information from SEVIRI channels (namely $0.6,0.8,3.9,10.8$ and $12.0 \mu \mathrm{m}$ ) together with information on illumination angles; it identifies the location and quantifies the radiative power of any hotspot present on land that radiates a heating signal within a pixel size of $1 \mathrm{~km}^{2}$ [73].

Analysis of the FIR Rapid Scan product performance during major wildfires in Greece for the period 2013-2018 highlighted the limited ability of the Meteorological Products Extraction Facility (MPEF) FIR algorithm to detect wildfires in coastal areas (Table 3). Greece and Cyprus, two of the DISARM partner countries, have extended coastlines; in particular, Greece has the most extensive coastline among all Mediterranean countries $(13780 \mathrm{~km})$, whereas Cyprus is the third largest Mediterranean island with a total coastline of $735 \mathrm{~km}$.

Table 3. MPEF Active Fire Monitoring (FIR) Rapid Scan evaluation for seven major coastal wildfires in Greece during 2013-2018 period. Numbers in parentheses indicate the corresponding locations in Figure 8 .

\begin{tabular}{|c|c|c|c|c|}
\hline Fire Event & Duration & \# of $5 \mathrm{~min}-\mathrm{Scans}$ & $\begin{array}{l}\text { \# of Successful } \\
\text { Scans }\end{array}$ & $\%$ Success \\
\hline Rhodes (1) & $\begin{array}{c}27 / 07 / 2013 \\
12.00-30 / 07 / 201300.00\end{array}$ & 120 & 0 & 0 \\
\hline Euboea (2) & $\begin{array}{c}30 / 07 / 2016 \\
09.00-31 / 07 / 201600.15\end{array}$ & 184 & 0 & 0 \\
\hline Chios (3) & $\begin{array}{c}25 / 07 / 2016 \\
00.00-25 / 07 / 201617.40\end{array}$ & 231 & 0 & 0 \\
\hline Thasos (4) & $\begin{array}{c}10 / 09 / 2016 \\
06.20-11 / 09 / 201620.15\end{array}$ & 456 & 0 & 0 \\
\hline Kalamos (5) & $\begin{array}{c}13 / 08 / 2017 \\
13.50-15 / 08 / 201703.00\end{array}$ & 447 & 364 & 81.4 \\
\hline Siteia (6) & $\begin{array}{c}12 / 07 / 2018 \\
08.05-12 / 07 / 201815.30\end{array}$ & 90 & 0 & 0 \\
\hline Mati (7) & $\begin{array}{c}23 / 07 / 2018 \\
14.05-23 / 07 / 201822.45\end{array}$ & 129 & 0 & 0 \\
\hline
\end{tabular}

The main issue identified in the performed retrospective analysis is that the resolution of SEVIRI data in conjunction with the restriction of the EUMETSAT FIR algorithm (a pixel needs to be at least one pixel length away from the nearest coastline/lake), excludes many coastal pixels from the FIR application. Consequently, with the FIR algorithm, wildfires in small and medium size islands and in areas which are not far enough from the coastline cannot be detected. This is a fact that EUMETSAT took into consideration for a potential improvement of the used algorithm. Figure 8 shows the pixel-wise extent (in grey) of the coastal area where the FIR algorithm cannot detect a wildfire.

Table 4. Modified algorithm evaluation every $15 \mathrm{~min}$ for three coastal wildfires in Greece during summer of 2019 in comparison with FIR, Fire Radiative Power (FRP), and FD\&M products. Numbers in parentheses indicate the corresponding locations in Figure 9.

\begin{tabular}{|c|c|c|c|c|c|c|}
\hline Fire Event & Fire Ignition (UTC) & $\begin{array}{c}\text { Modified } \\
\text { Algorithm First } \\
\text { Detection }\end{array}$ & $\begin{array}{l}\text { \# Modified } \\
\text { Algorithm }\end{array}$ & FIR & FRP & FD\&M \\
\hline Elafonisos (8) & $10 / 08 / 201905.00$ & 06.30 & $69 / 97$ & No detection & No detection & No detection \\
\hline Euboea (2) & 13/13/08/2019 00.00 & 00.15 & $95 / 96$ & No Detection & $49 / 96$ & $71 / 96$ \\
\hline
\end{tabular}




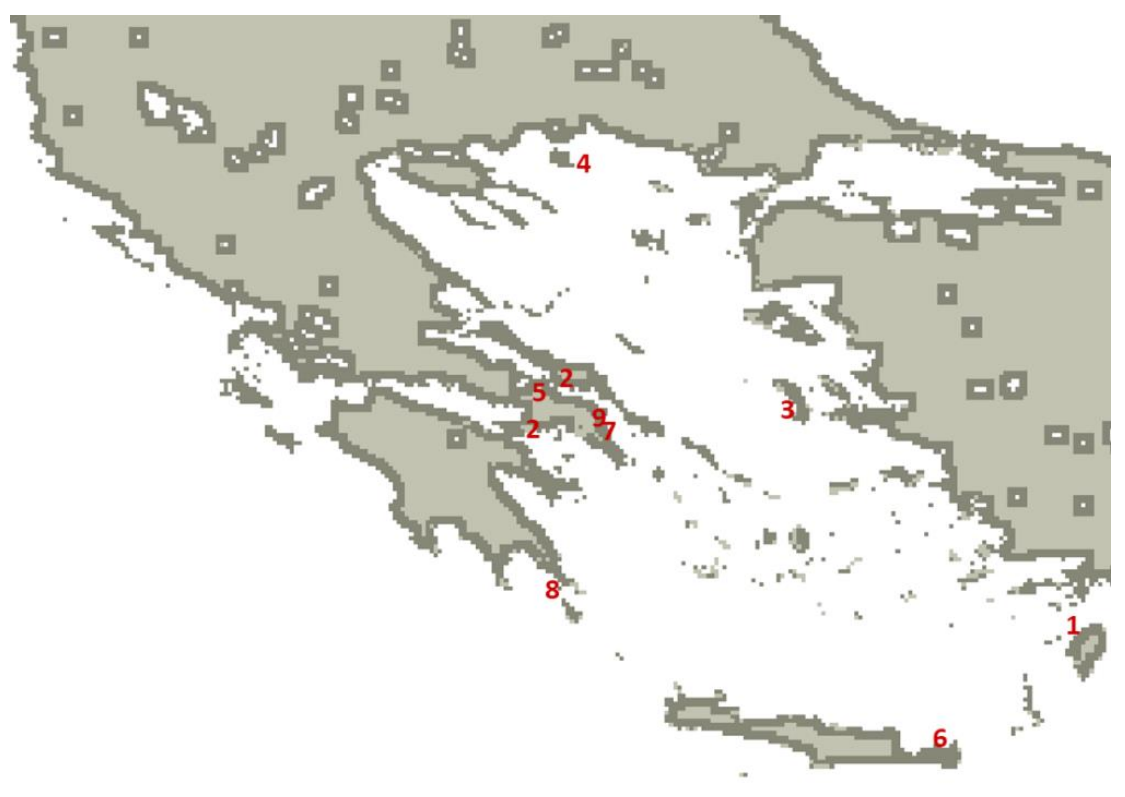

No estimation (pixel close to water)

Figure 8. Delineation of the areas (in grey) where the detection of wildfires is not possible with the use of the FIR algorithm. Numbers indicate the areas mentioned in Tables 3 and 4.

The limited capacity to detect wildfires in the coastal environment is also recognized in the cases of the FD\&M and FRP products. An example depicting the above situation is presented in Figure 9 and refers to wildfires that occurred in the region of Attica, Greece on 23 July 2018. During that day, two fire events occurred in the region of Attica: The Kineta fire (west of Athens) and the Mati fire (northeast of Athens, [6]). Although the IR3.9 channel (Figure 9a) depicts both fires at 14:30 UTC, the FD\&M product (Figure 9b) detected only the Kineta fire, while FIR and FRP products failed to detect any of these two fire events. It should be mentioned that the capacity of the IR3.9 channel to detect wildfires is due to its high temperature sensitivity, a fact implying that hot spots are easily detected, as well as to the negligible absorption by atmospheric humidity. On the contrary, the spectral band of $3.9 \mu \mathrm{m}$ is close to a $\mathrm{CO}_{2}$ absorption band, a fact that results in a 4-7 Kelvin signal reduction.

Considering the above, in an effort to overcome the aforementioned fire detection and monitoring problems, a modified FIR version was developed and tested both retrospectively and in real-time wildfires. The modifications from the original FIR algorithm concern the removal of the standard deviation tests and the tuning of the thresholds used for the infrared channels so as the application of the algorithm in coastal pixels to be effective. However, it should be noted that the above modifications resulted in the increase of false alarms at areas characterized by non-forested land cover types. To this end, to account for the high land surface temperatures, the use of a vegetated/non-vegetated mask was considered as necessary. The application of the mask reduced the false alarms significantly (by $40 \%$ ).

The modified algorithm was tested in three coastal wildfires in Greece during August 2019. The results verified the ability of the modified algorithm to detect and monitor coastal fires compared to the original algorithm (Table 4). Take note that Elafonisos is a small island in southern Greece, with an area of only $18 \mathrm{~km}^{2}$.

Based on the above, an automated procedure was tested, taking note of the need to differentiate the criteria of the detection algorithm depending on the location of the wildfire area, i.e., if the area is in the pixel size proximity to the coastline or in the mainland. 
Ch.4 IR3.9 (pixel counts)

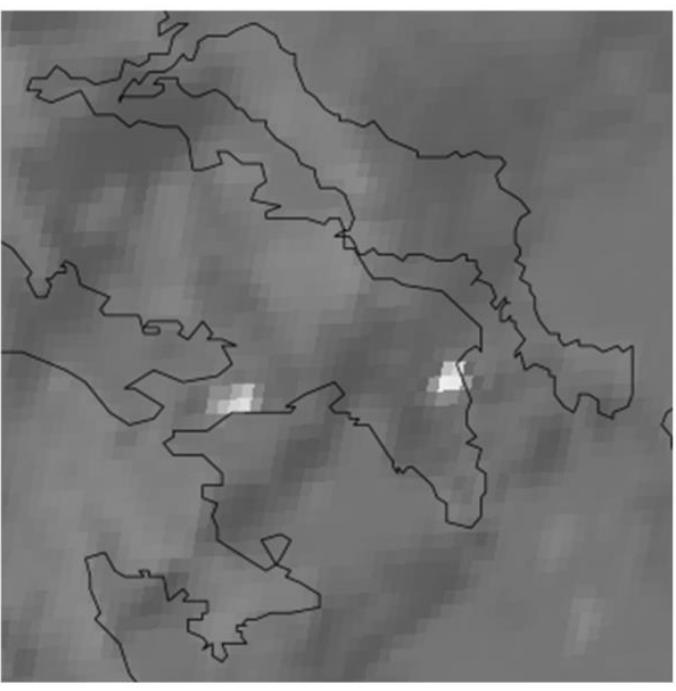

Strong signal from IR3.9

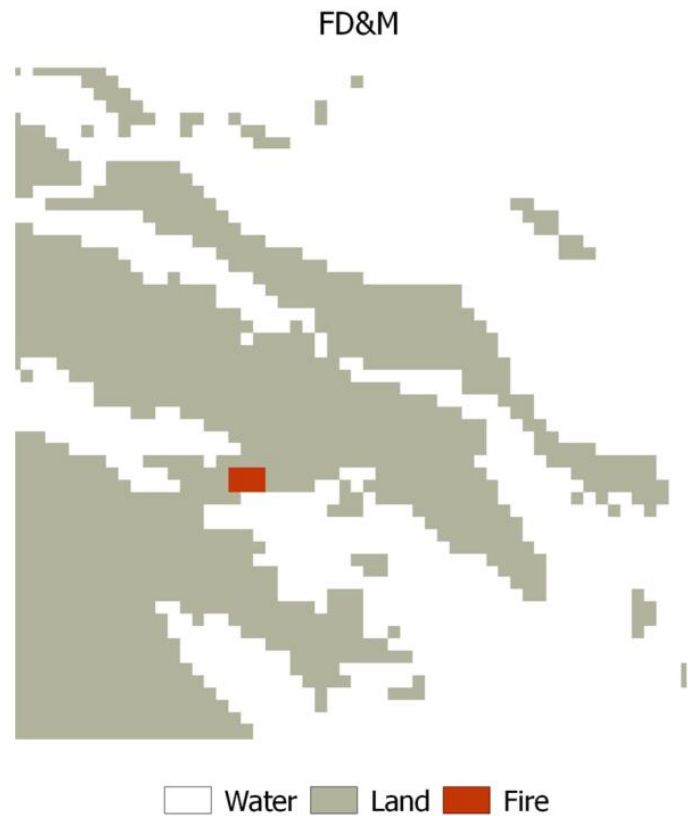

(b)

Figure 9. Wildfires in the Attica region, Greece at 14:30 UTC on 23 July 2018 as depicted in (a) the IR3.9 channel and (b) the Fire Detection and Monitoring (FD\&M) product.

\section{Rapid Response System for Fire Spread Forecasting}

The development of the rapid-response fire spread forecasting system IRIS began in early autumn of 2017. The system was pre-operationally deployed and calibrated over Greece during the 2018 fire season, and operationally implemented during the 2019 fire season, in collaboration with the Hellenic Fire Corps. The operational implementation consists of the following steps:

- For each ignited fire with potential danger, the HFC introduced the coordinates and the time of the ignition into a web-based application developed in the frame of DISARM.

- Once this information is submitted, the operational launch of IRIS system at the computing infrastructure of the National Observatory of Athens (NOA) is initiated.

- The modeling domains are built around the ignition point and IRIS is run for 24-model hours.

- The output, in dynamic Google Earth KMZ files, showing the simulated fire spread is communicated automatically to the HFC in 15-min since the initial launch providing forecasts for the next 6-h and in $60 \mathrm{~min}$ providing forecasts for the next 24-h.

A detailed description of the system components, procedures, and calibration has already been provided by [74]. In this work, we focus on the verification of the operational use of IRIS during the 2019 fire season.

During the 2019 fire season, IRIS rapid response fire spread forecasting system was activated by the HFC in order to provide fire spread forecasts for 17 wildfires in total. The locations of these events are shown in Figure 10. The main characteristics of these events are summarized in Table 5. Eleven events occurred in August, and 3 during July/September. For 8 out of the total 17 events, it was possible to retrieve satellite-based data on the burnt area (BA). The data were retrieved from the European Forest Fire Information System (EFFIS; https://effis.jrc.ec.europa.eu) and are based on satellite imagery from the Moderate Resolution Imaging Spectroradiometer (MODIS), onboard the Terra and Aqua satellites. As shown in Table 5, the most significant event of the 2019 fire season was the wildfire in central Euboea (072019) that burned an area of about 3000 ha, followed by the wildfires in Zakynthos (162019) and Boeotia (082019), which burned more than 700 ha. 


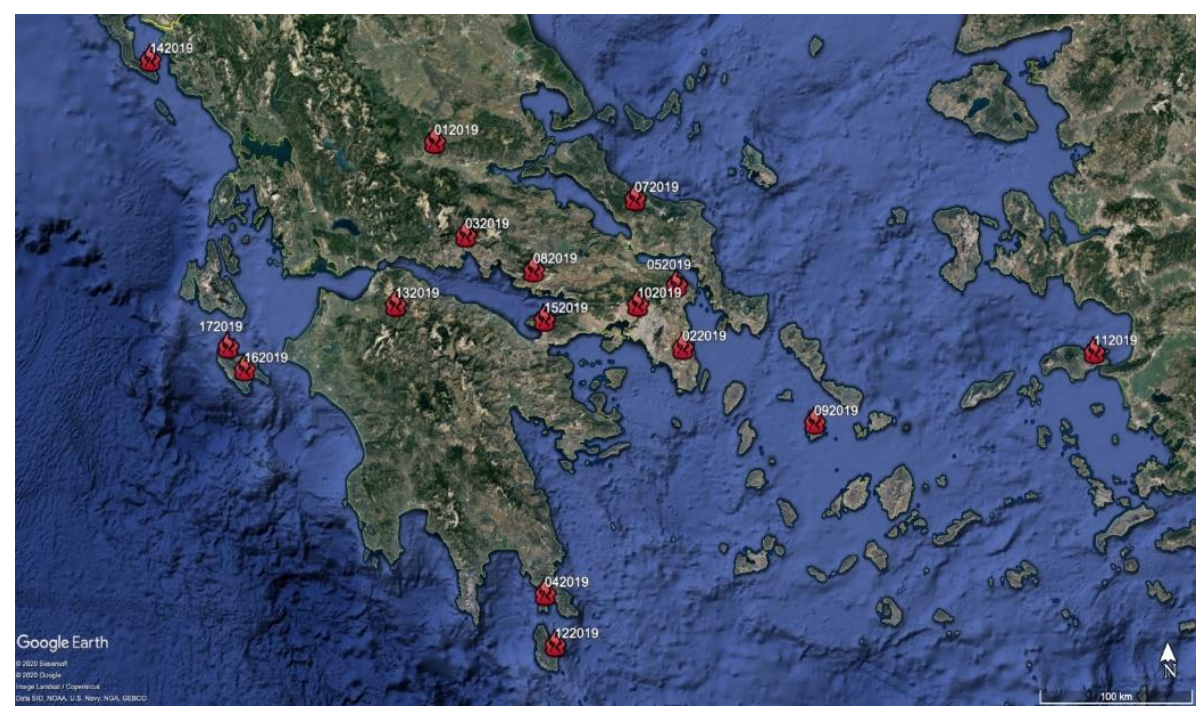

Figure 10. Locations of the 17 wildfire events for which IRIS was activated and provided fire spread forecasts during the 2019 fire season.

For the accurate assessment of the IRIS fire spread forecasts, we employed the methodology detailed in [75]. In brief, we constructed error matrices between predicted and observed BA, and computed the frequency of occurrence of each case (i.e., presence/absence of BA). Three statistical measures of accuracy were subsequently calculated, namely the Kappa Coefficient (KC; [76]), the Sorensen Coefficient (SC; [77]), and the Overestimation Index (OI; [75]). KC and SC allow the evaluation of the overall agreement between the observed and observed fire perimeters, while OI provides a measure of the model's tendency to over/under-predict BA. Additionally we computed the absolute metrics of Burnt Area Agreement (BAA), Overestimation (BAO), and Underestimation (BAU).

Table 5 summarizes the statistical analysis of IRIS' fire spread forecasts for the 2019 fire season. Overall, the results suggest a satisfactory performance. For all examined wildfires, IRIS was able to predict the final spatial extent better than by random chance $(p \leq 0.05, \mathrm{KC})$. In particular, the computed $\mathrm{KC}$ and SC values indicate moderate agreement (i.e., $(0.4,0.6))$ between the predicted and actual fire perimeters for all events, except for wildfire 012019 , for which they suggest substantial agreement (i.e., $(0.6,0.8))$. Not surprisingly, BA was overestimated in all wildfires, since firefighting activities are not taken into account during the simulation of the spread (i.e., IRIS provides a worst-case forecast of fire spread).

The most significant wildfire of the 2019 fire season was inarguably the 072019 event, which took place over Euboea island on 13-14 August 2019. This particular wildfire broke out early in the morning in central Euboea and burned approximately 3000 ha in $\sim 24 \mathrm{~h}$. In addition, this wildfire produced large amounts of smoke that during the first day (13 August 2019) were transported over the Attica basin, forcing the authorities to issue warnings in order to protect vulnerable population groups (elders, infants, people with respiratory diseases). Figure 11 shows the visual comparison between the final actual and predicted fire perimeters. Clearly, IRIS was able to successfully predict the southward and eastward propagation of the fire. However, it significantly underestimated fire spread north of the ignition location. This could partially be attributed to the uncertainty of the actual location of the ignition. Specifically, ignition locations are provided in IRIS based on the coordinates given by the first arriving firefighting crew, following the notification for a wildfire. On certain cases, this could result in significant differences between the actual ignition point and the one provided (activation of IRIS). Nevertheless, even with this compromise in accuracy, IRIS is clearly capable of providing useful guidance with respect to the expected spread of a wildfire. 
Table 5. Summary of the 17 wildfires for which IRIS was activated and provided fire spread forecasts during the 2019 fire season. Burnt area (BA) estimates (in ha) and verification statistics are provided for those events for which remote sensing data were available. The presented statistics include the Kappa Coefficient (KC), the Sorensen Coefficient (SC), the Overestimation Index (OI), and the BA Agreement (BAA, in ha), Overestimation (BAO, in ha), and Underestimation (BAU, in ha). Values of KC followed by * indicate statistically significant accuracy (Z-test; [78]) at $p \leq 0.05$.

\begin{tabular}{cccccccccc}
\hline ID & Datetime & Region & BA & KC & SC & OI & BAA & BAO & BAU \\
\hline 012019 & $08 / 07 / 201912: 40$ & Phthiotis & 98 & $0.63^{*}$ & 0.68 & 0.44 & 75 & 52 & 20 \\
\hline 022019 & $29 / 07 / 201911: 40$ & Attica & - & - & - & - & - & - & - \\
\hline 032019 & $29 / 07 / 201912: 10$ & Boeotia & - & - & - & - & - & - & - \\
\hline 042019 & $10 / 08 / 201906: 55$ & Laconia & 535 & $0.45^{*}$ & 0.49 & 0.06 & 268 & 298 & 266 \\
\hline 052019 & $10 / 08 / 201912: 35$ & Attica & - & - & - & - & - & - & - \\
\hline 062019 & $12 / 08 / 201901: 30$ & Attica & 180 & $0.45^{*}$ & 0.48 & 0.45 & 114 & 180 & 68 \\
\hline 072019 & $13 / 08 / 201901: 25$ & Euboea & 2889 & $0.52^{*}$ & 0.57 & 0.32 & 1899 & 1908 & 989 \\
\hline 082019 & $13 / 08 / 201903: 40$ & Boeotia & 735 & $0.57^{*}$ & 0.60 & 0.93 & 702 & 909 & 35 \\
\hline 092019 & $19 / 08 / 201911: 40$ & Cyclades & - & - & - & - & - & - & - \\
\hline 102019 & $24 / 08 / 201910: 50$ & Attica & - & - & - & - & - & - & - \\
\hline 112019 & $24 / 08 / 201914: 50$ & Samos & 59 & $0.49^{*}$ & 0.52 & 0.96 & 57 & 104 & 2 \\
\hline 122019 & $24 / 08 / 201919: 05$ & Kythira & - & - & - & - & - & - & - \\
\hline 132019 & $25 / 08 / 201911: 40$ & Achaea & - & - & - & - & - & - & - \\
\hline 142019 & $27 / 08 / 201914: 50$ & Corfu & - & - & - & - & - & - & - \\
\hline 152019 & $14 / 09 / 201913: 30$ & Corinthia & 352 & $0.42^{*}$ & 0.46 & 0.79 & 283 & 604 & 71 \\
\hline 162019 & $15 / 09 / 201908: 03$ & Zakynthos & 919 & $0.52^{*}$ & 0.55 & 0.84 & 814 & 1217 & 103 \\
\hline 172019 & $17 / 09 / 201914: 00$ & Zakynthos & - & - & - & - & - & - & - \\
\hline
\end{tabular}

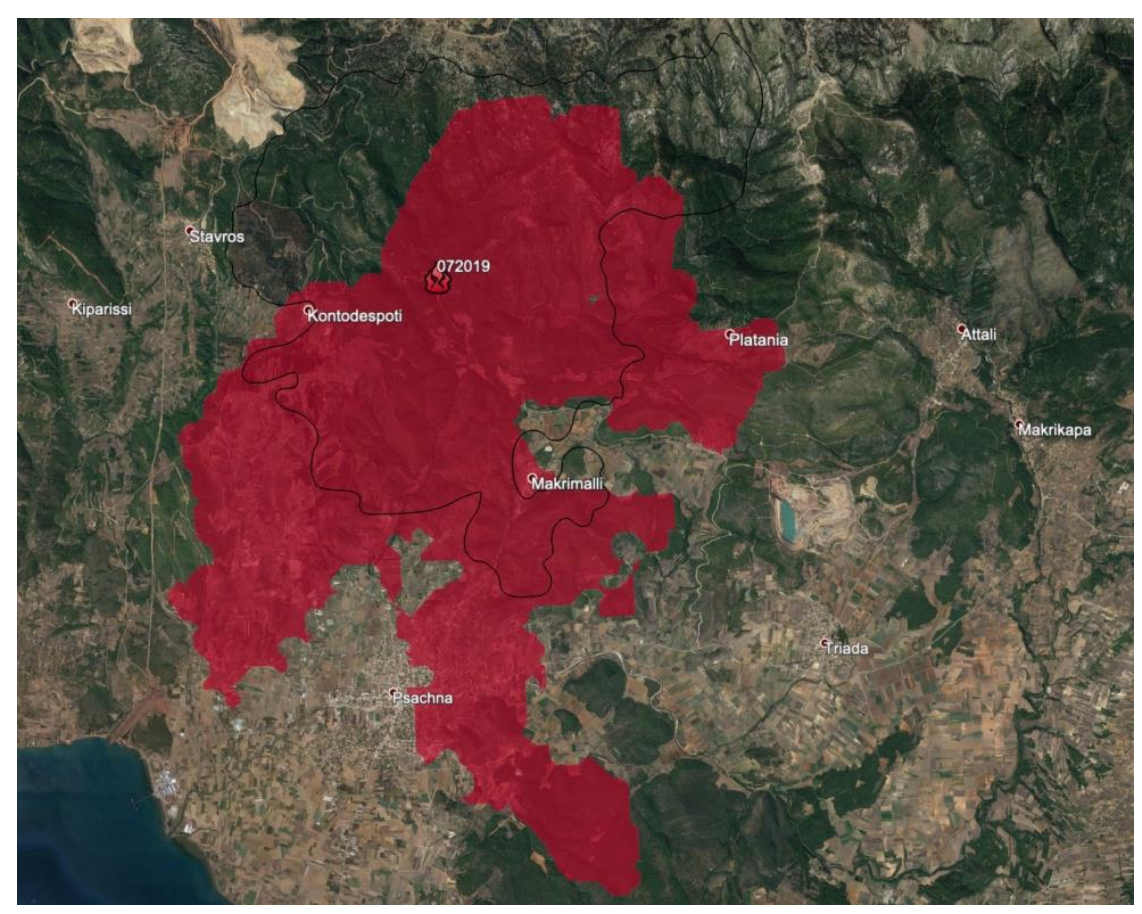

Figure 11. Visual comparison of the final actual (black line) and predicted (red shade) fire perimeter for wildfire 072,019 in central Euboea. Flame icon denotes the ignition location. 


\section{Future Projections of Wildfire Danger in the Balkan Mediterranean Area}

In order to address the fire related climatic aspects and in accordance to DISARM objectives, a climatic component has been developed as the fourth pillar of the DISARM early warning system. The system provides fire danger and drought assessments over the study area for the near future (2021-2050), based on state-of-the-art regional climate model simulations under two emission scenarios. For the assessment of the fire danger, several meteorological based indices (CFWI, FFWI, SAI) have been used. For the drought assessment, the Stardardized Precipitation Index (SPI) has been employed. To calculate the aforementioned indices, 3-hourly climatic data of air temperature, relative humidity, wind speed, and $24 \mathrm{~h}$ precipitation of three RCM/GCM couples (horizontal resolution of 0.11 degrees) developed within the European branch of the Coordinating Regional Climate Downscaling Experiment (EURO-CORDEX) initiative have been utilized. For the calculations of the SPI monthly precipitation sums for the period 1971-2050 were obtained.

These pairs comprise the RCA4 regional climate model (RCM) of the Swedish Meteorological and Hydrological Institute (SMHI) [79] driven by 3 different Global Climate Models (GCMs): (i) The Hadley Centre Global Environmental Model version 2 Earth System called HadGEM2-ES [80,81] of the Met Office Hadley Centre (MOHC), (ii) the Max Planck Institute for Meteorology model MPI-ESM-LR [82], and (iii) the CNRM-CM5 model [83] of the Météo France National Centre for Meteorological Research (CNRM) and CERFACS (Centre Européen de Recherche et de Formation Avancée en Calcul Scientifique) group.

Current simulations cover the period 1971-2000, and function as reference for comparison with future projections for the period 2021-2050. Future projections are based on two emission scenarios, (i) the stabilization RCP4.5 scenario and (ii) the business-as-usual RCP8.5 scenario. Within the platform, geographical maps of the three countries depicting current climatic fire danger and drought conditions, as well as their changes in the near future for each RCM/GCM pair, under the two emission scenarios have been developed.

The indices calculated within the framework of DISARM project, as well as the climatic input needed for their calculation are presented in Table 6. It should be noted that fire danger calculations refer only to the summer period when most fires in the Balkan-Mediterranean area occur. Moreover, as far as CFWI threshold indices are concerned, the thresholds for Cyprus and Bulgaria are based on EFFIS homogenous classification for the European domain. For Greece, the fire danger classes developed within the DISARM project have been used as more representative for the area [47]. Here we focus on the (FWI_nl1) classification that has been also used in the discussion of the seasonal forecasts (Section 3.3).

Table 6. Fire danger and drought indices provided within the climatic component of DISARM early warning system and the input data needed for their calculation.

\begin{tabular}{|c|c|c|}
\hline Index Name & Indices Produced & Input Variables \\
\hline $\begin{array}{l}\text { Canadian Fire Weather Index } \\
\text { (CFWI) }\end{array}$ & $\begin{array}{c}\text { Mean summer CFWI } \\
\text { Number of days with } \\
\text { moderate/high/very high CFWI } \\
\text { values (based on EFFIS and } \\
\text { DISARM FWI_nl1 classification) }\end{array}$ & $\begin{array}{c}\text { air-temperature, relative humidity, } \\
\text { and wind speed at } 12 \mathrm{UTC}, 24 \mathrm{~h} \\
\text { precipitation }\end{array}$ \\
\hline Fosberg Fire Weather Index (FFWI) & Mean summer FFWI & $\begin{array}{l}\text { air temperature, relative humidity, } \\
\text { and wind speed at } 12 \text { UTC }\end{array}$ \\
\hline Swedish Angstrom Index (SAI) & $\begin{array}{c}\text { Fire occurrence very likely/fire } \\
\text { conditions favorable/fire } \\
\text { conditions unfavorable/fire } \\
\text { occurrence unlikely }\end{array}$ & $\begin{array}{l}\text { air temperature and relative } \\
\text { humidity at } 12 \text { UTC }\end{array}$ \\
\hline $\begin{array}{l}\text { Standardized Precipitation Index } \\
\text { (SPI) }\end{array}$ & $\begin{array}{l}\text { Number of years with dry } \\
\text { conditions (SPI- } 6 \text { at the end of } \\
\text { September }<-1)\end{array}$ & monthly total precipitation \\
\hline
\end{tabular}


As far as the fire danger indices are concerned, increase in fire danger potential is projected for the majority of analyzed indices and models for the three countries under both emission scenarios. For brevity (Figure 12), indicative maps of fire danger and drought projections for the three countries are presented in the early warning system platform of DISARM (www.disarmfire.eu).

For Greece, the spatial distribution of the highest increases varies depending on the model and the scenario. Nonetheless, consensus among the majority of the models is found in some parts of northern continental Greece, Peloponnese, Crete, and the Aegean islands under RCP4.5. For these parts, the highest increases in the number of days with very high CFWI values (CFWI $>75$ ), according to the modified thresholds for the country, will reach 20 extra days per year. For the greater part of the country, 10 to 20 additional days with very likely fire occurrence conditions $(\mathrm{SAI}<2.0)$ for two out of three models (RCA4/MOHC-HadGEM2-ES and RCA4/MPI-M-MPI-ESM-LR) under the business-as-usual scenario, is expected.

In Bulgaria, the highest increases differ and they are dependent on the model and the scenario. In particular, for RCA4/MOHC-HadGEM2-ES, greater increases in the number of days with 'very high' fire danger CFWI values (CFWI $>38$ ) of about 10 to 20 days/year are found under RCP4.5 almost for the entire country, while for RCA4/MPI-M-MPI-ESM-LR, this is true under RCP8.5. The highest increases of up to 30 days per year in the number of days with very likely occurrence conditions are projected by RCA4/MPI-M-MPI-ESM-LR under RCP8.5, while for the northern and central parts, small decreases of up to 7 days/year under both scenarios are projected by RCA4/CNRM-CM5.

Regarding Cyprus, the highest increases in the number of 'very high' fire danger days (CFWI>38) of 20-30 days/year for the eastern and western parts are projected by RCA4/MOHC-HadGEM2-ES under the 'business as usual' scenario. According to this model, the highest increases in the number of days with SAI $<2.0$ of up to an extra month is projected for the larger part of the island, for both scenarios.

Concerning the SPI projections, an increase in the number of years with dry conditions is projected over the three countries with the highest increases reaching 10 to 12 extra years during the period 2021-2050 under both scenarios.

In Greece, the spatial distribution of the highest increases varies depending on the model and the scenario, and, as in the case of fire danger, a consensus among the majority of the models is noticed in some parts of central Greece, Peloponnese, Crete, and the Aegean islands mostly under RCP4.5. In Bulgaria, the highest increases are found in the central and the northeastern areas of the country under both scenarios for two out of the three models (RCA4/MOHC-HadGEM2-ES and RCA4/MPI-M-MPI-ESM-LR). According to the third model (RCA4/CNMRM-CM5), decreases in the number of years are shown, 2 to 4 years, in the northern areas of the country, while decreases of the same magnitude are found for the southeastern areas. Regarding Cyprus, the highest increases vary depending not only on the model, but also the scenario. In particular, for the RCA4/CNRM-CM5 highest increases are shown under RCP4.5 covering almost the whole island, while under RCP8.5 the highest increases are found in the central and northeastern part of the island, including the whole Troodos mountain range. On the contrary, for the RCA4/MOHC-HadGEM2-ES, the highest increases are projected under RCP8.5 in the western and northeastern areas of the island, while under RCP4.5 the highest increases are lower (4-6 extra years) for the greater part of the island. 


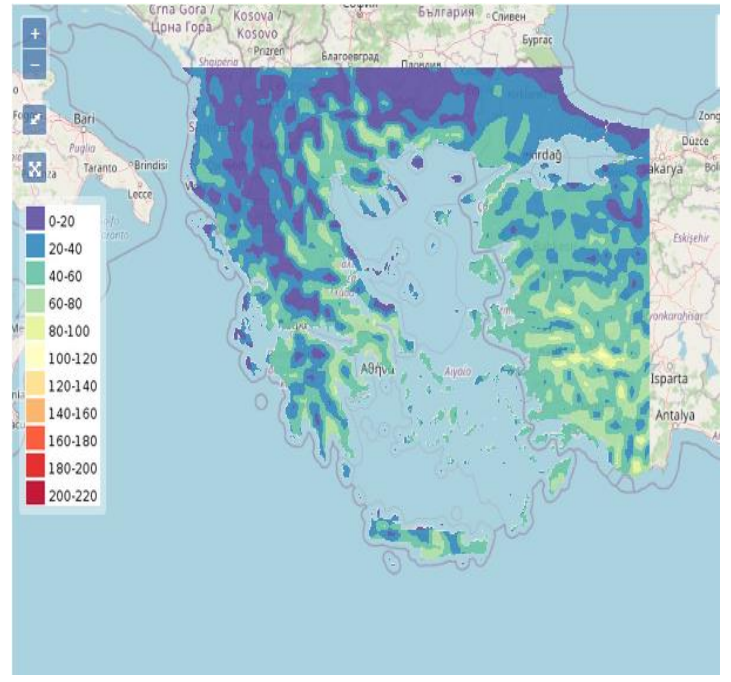

(a)

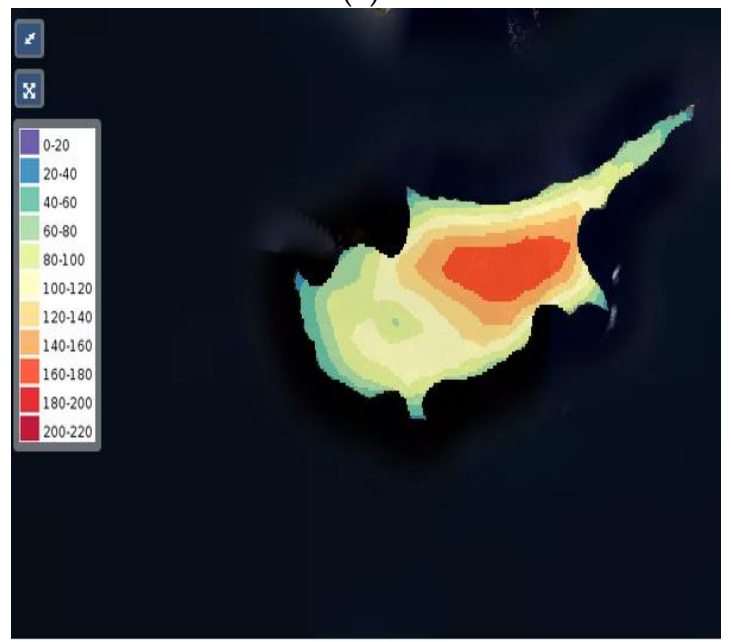

(c)

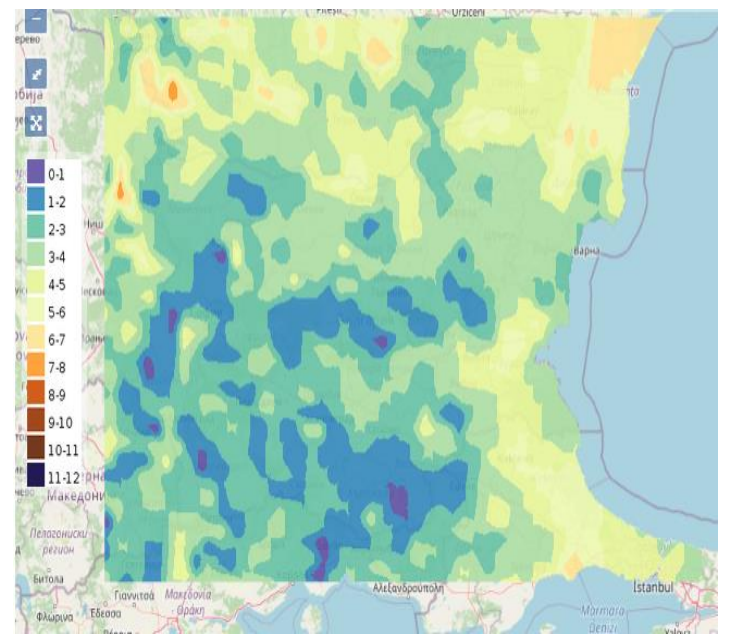

(e)

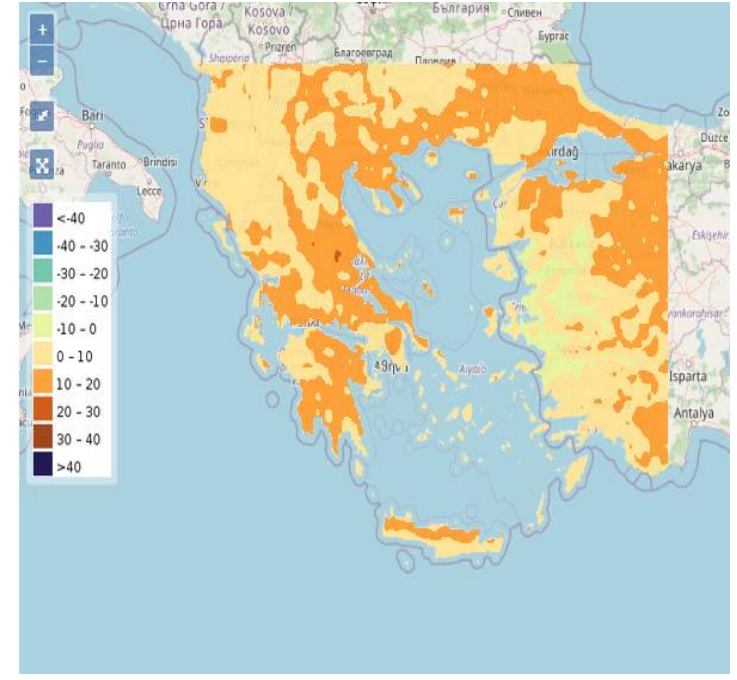

(b)

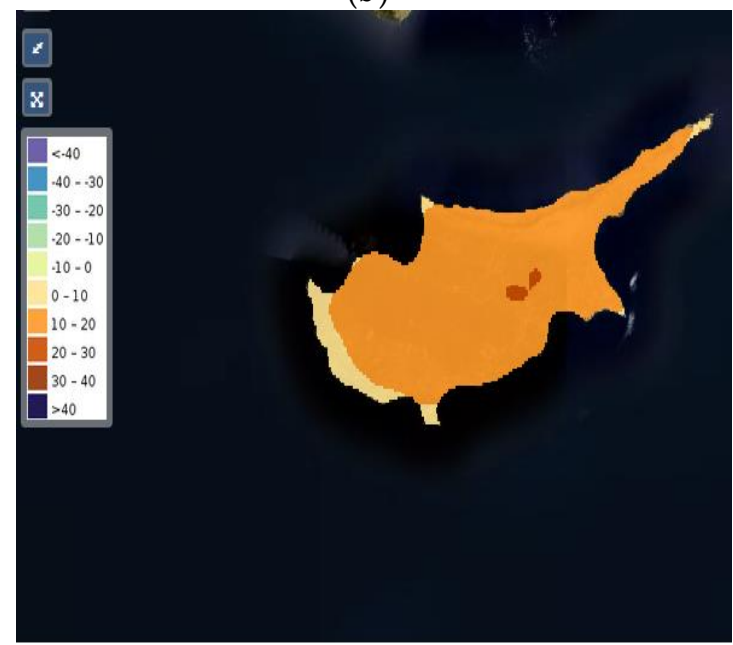

(d)

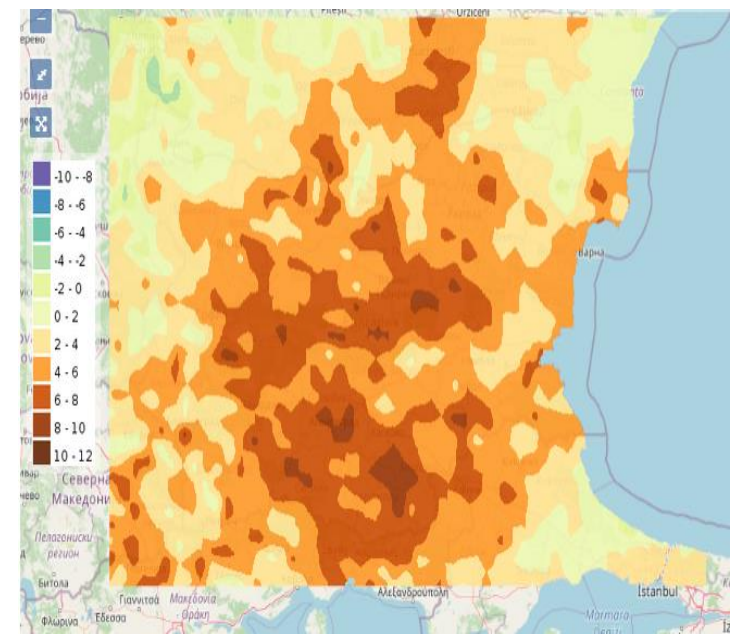

(f)

Figure 12. Differences (right column) between the future period (2021-2050) and the control period (left column) in: (upper row) Number of days with high CFWI values in Greece based on RCA4/MPI-M-MPI-ESM-LR projections under RCP8.5, (middle row) number of days with very likely fire occurrence according to SAI based on RCA4/MPI-M-MPI-ESM-LR under RCP4.5, (lower row) number of years with SPI6 <-1 in Bulgaria based on RCA4/MPI-M-MPI-ESM-LR projections under RCP8.5. 


\section{Discussion}

The early warning system developed within the framework of the project has highlighted some important best practices, innovative tools, and prospects for research and replicability issues.

More specifically, as it concerns fire weather danger forecasting, the analysis has shown that once a fire weather index is used in different geographical areas, a proper adjustment of the wildfire danger classification is necessary in order to account for local climate conditions. In the case of DISARM and for the countries of Greece, Bulgaria, and Cyprus, the Canadian Fire Weather Index thresholds for wildfire danger have been adapted. The establishment of appropriate wildfire danger thresholds allows the public authorities and citizens to take timely prevention measures and to effectively react during a crisis. As it has been also highlighted in the literature, fuel moisture plays a decisive role on the possibility and properties of ignition and spread of wildfires [50]. The application over Bulgaria has shown that modeling of fuel dryness related to soil-vegetation dynamic state is a promising approach to reflect live vegetation input to landscape flammability. Moreover, live vegetation dryness may provide better estimation of landscape fire danger. For the forecasting of fire danger at monthly and seasonal scale, we have used in our analysis an exploratory methodology similar to the one used at the US CEFA Desert Research Institute (https://cefa.dri.edu/CFS/fwi.php) based on the 6-hourly CFSv2 hindcast sub-daily reference climatology and the 6-hourly, 9-month lead time daily operational forecasts. The analysis highlighted that there is still consideration on the potential of seasonal forecasts of fire weather risk, which relates to the coarse horizontal resolution of the global models and the limited ability to accurately resolve physical processes (e.g., convection) taking place at sub-grid scales. Dynamical and statistical downscaling combined with probabilistic approaches may enhance the validity of the long-term, seasonal wildfire danger predictions [65].

The work performed under the second pillar of DISARM early warning system was devoted to satellite early detection and monitoring of wildfires. The analysis has shown that the algorithm developed under the DISARM framework was able to detect wildfires over islands and near the coastline that other EUMETSAT (FIR) and LSA-SAF (FD\&M and FRP) products did not. Furthermore, it detects fires $15 \mathrm{~min}$ to $90 \mathrm{~min}$ after the fire ignition, as reported by the fire service, a fact which may be highly supportive for wildfires in distant and isolated areas with limited, if any, ground monitoring. On the other hand, the application of the algorithm may increase the number of detected false alarms that occur in non-forested land cover types in the mainland in periods of extreme thermal events associated with high land surface temperatures; however the number of false alarms was reduced by $40 \%$ by using a vegetated/non vegetated mask. Finally the developed algorithm can be combined with the FIR application in the mainland, for the detection of wildfires in all land areas, regardless of the distance from the coast on the one hand and avoiding false alarms on the other.

Recent works presented in the literature $[74,84-86]$ have highlighted that current high-performance infrastructure, available in many institutions, can support the operational use of coupled atmosphere-fire spread models for the prediction of fine- to large-scale effects of wildfires. A cornerstone of DISARM project was the development and operational application of the rapid response fire spread forecasting system IRIS. Validation of the operational application of IRIS for the 2019 fire season in Greece has shown a moderate agreement between the predicted and the actual fire perimeters. On the other hand, the predicted burnt area was always overestimated since firefighting activities are not considered by the system. Our analysis has shown that a coupled atmosphere-fire modeling system such as IRIS, if properly adapted for the representation of fuels, can be a valuable tool, providing support to the fire services during fire suppression. To our knowledge, IRIS is among the very few coupled modeling systems operationally implemented worldwide (e.g., [84-86]).

At this point, two further achievements of DISARM project should also be mentioned. Firstly, as a result of efforts of Greece, Bulgaria, and Cyprus to establish a common strategic framework for tackling the challenges posed by drought and wildfires in the frame of DISARM project, the interest of the consortium to use the new version of the FRM product has been expressed with a relevant request to LSA-SAF. Consequently, the LSA-SAF consortium rearranged their operational chain so that all 
DISARM countries are included in the domain of the new FDI product for future operational access. Secondly, EUMETSAT acknowledged the fact that the FIR algorithm cannot detect wildfires in small, medium size islands and in coastal areas, and therefore will consider, in the near future, potential improvements of the used algorithm.

Last, but not least, the wealth of information provided by the analysis of future fire danger projections indicates that regional authorities could take advantage of these data for the development of proper regional adaptation strategies to climate change.

\section{Concluding Remarks and Prospects}

Wildfires constitute a major threat to the sustainable development of countries and are recognized for their adverse impacts on communities, infrastructures, and cultural/environmental protected areas. Their intensification due to climate change increases the need for the affected countries to further develop appropriate prevention/mitigation strategies and useful tools. To this direction, the DISARM project has already been successfully implemented through transnational collaboration between three countries in the Balkan Peninsula and Eastern Mediterranean (Greece, Bulgaria, and Cyprus). The established transnational collaboration network has proved to be very fruitful in various levels, especially by:

- Exchanging knowledge and experiences to reach a better specification of the requirements and a joint action plan towards the development of common practices and tools.

- Designing appropriate protocols for methods' harmonization. This is an essential step for ensuring the delivery of a consolidated set of services.

- Increasing the awareness of both public authorities and general public through joint dissemination activities.

- Contributing in the protection of life, property, and essential infrastructure through the use of the operational tools and information incorporating best practices of each country.

The Balkan and East Mediterranean region encompasses vulnerable ecosystems susceptible to extended periods of drought while wildfires are expected to be further intensified by climate change. Therefore, the combined use of operational long-term wildfire hazard forecasts (e.g., the CFWI) and identified methods aiming to refine the fire danger and fire spread predictions, may provide valuable information to the decision support systems and wildfire management services, which have the responsibility of preventing wildfire disasters. Namely, the DISARM early warning system is targeting four main groups of users: (a) Regional public authorities, which could take advantage of the fire danger forecasts by setting up and scheduling more effective strategies, e.g., against the accumulation of burning fuel (dead biomass) in the areas of interest; (b) civil protection agencies and fire services, which based on the near real-time monitoring of fire activity and modeling of wildfires spread, could not only significantly increase their capacity to combat wildfires, but also to inform and protect the population in danger; (c) private sector stakeholders, and (d) the general public, which could use the provided information as a means of their own protection against potential threats. Based on the aforementioned added value benefits from the use of the system, the consortium committed to continue its contribution via data sharing and provision, for the next, at least, 5 years.

Author Contributions: Conceptualization, V.K.; methodology, V.K., C.C., S.M., J.S., F.T., A.B., T.C., S.D., C.G. (Christos Giannakopoulos), T.M.G., C.G. (Christo Georgiev), A.K. (Athanasios Karagiannidis), A.K. (Anna Karali), I.K., K.L., I.L., T.M., K.P., A.P., Y.P.; software, visualization, A.B., S.D., T.G., A.K. (Athanasios Karagiannidis), A.K. (Anna Karali), T.M., A.P., Y.P.; investigation, V.K., C.C., S.M., J.S., F.T., A.B., T.C., S.D., C.G. (Christos Giannakopoulos), T.M.G., C.G. (Christo Georgiev), A.K. (Athanasios Karagiannidis), A.K. (Anna Karali), I.K., K.L., I.L., T.M., K.P., A.P., Y.P.; writing—original draft preparation-review and editing, V.K., C.C., S.M., J.S., F.T., A.B., T.C., S.D., C.G. (Christos Giannakopoulos), T.M.G., C.G. (Christo Georgiev), A.K. (Athanasios Karagiannidis), A.K. (Anna Karali), I.K., K.L., I.L., T.M., K.P., A.P., Y.P.; supervision and funding acquisition, V.K. All authors have read and agreed to the published version of the manuscript. 
Funding: This research was co-funded by the European Union (European Research Development Fund \& Instrument for Pre-accession Assistance) and National Funds of the participating countries, under the INTERREG Balkan-Mediterranean 2014-2020 cooperation programme (program DISARM).

Acknowledgments: The study on the quality of the fire danger index for the domain of Bulgaria was supported by EUMETSAT LSA-SAF in the frame of CDOP-3 Project. LSA-SAF is acknowledged for provision of Fire Danger Index data for the whole DISARM domain. The authors thank Th. Baimpos for proof reading the manuscript.

Conflicts of Interest: The authors declare no conflict of interest.

\section{References}

1. East Bay Times. Available online: https://www.eastbaytimes.com/2018/11/11/crews-continue-to-battlestrong-winds-in-deadly-camp-fire/ (accessed on 1 July 2020).

2. Cruz, M.G.; Sullivan, A.L.; Gould, J.S.; Sims, N.C.; Bannister, A.J.; Hollis, J.J.; Hurley, R.J. Anatomy of a catastrophic wildfire: The Black Saturday Kilmore East fire in Victoria, Australia. For. Ecol. Manag. 2012, 284, 269-285. [CrossRef]

3. Ferreira-Leite, F.; Bento-Gonçalves, A.; Vieira, A.; Vinha, L. Mega-fires around the world: A literature review. In Wildland Fires: A Worldwide Reality; Bento-Gonçalves, A.J., Vieira, A.A.B., Eds.; Nova Science Publishers: New York, NY, USA, 2015; p. 239. ISBN 978-1-63483-397-4.

4. Pereira, J.; Alexandre, P.; Campagnolo, L.; Bar-Massada, A.; Radeloff, V.; Silva, P. Defining and mapping the wildland-urban interface in Portugal. Adv. For. Fire Res. 2018, 2018, 742-749. [CrossRef]

5. Tedim, F.; Xanthopoulos, G.; Leone, V. Forest fires in Europe: Facts and challenges. Wildfire Hazards Risks Disasters 2015, 77-99. [CrossRef]

6. Lagouvardos, K.; Kotroni, V.; Giannaros, T.M.; Dafis, S. Meteorological Conditions Conducive to the Rapid Spread of the Deadly Wildfire in Eastern Attica, Greece. Bull. Am. Meteorol. Soc. 2019, 100, 2137-2145. [CrossRef]

7. Ribeiro, L.M.; Domingos, X.V.; Miguel, A.; McGee, T.K.; Pereira, M.G.; Parente, J.; Xanthopoulos, G.; Leone, V.; Delogu, G.M.; Hardin, H. Extreme wildfires and disasters around the world: Lessons to be learned. In Extreme Wildfire Events and Disasters; Elsevier: Amsterdam, The Netherlands, 2020; pp. 31-51. [CrossRef]

8. Bedia, J.; Herrera, S.; Gutiérrez, J.M.; Zavala, G.; Urbieta, I.R.; Moreno, J.M.; García, S.H. Sensitivity of fire weather index to different reanalysis products in the Iberian Peninsula. Nat. Hazards Earth Syst. Sci. 2012, 12, 699-708. [CrossRef]

9. Carvalho, A.; Flannigan, M.D.; Logan, K.A.; Gowman, L.M.; Miranda, A.I.; Borrego, C. The impact of spatial resolution on area burned and fire occurrence projections in Portugal under climate change. Clim. Chang. 2009, 98, 177-197. [CrossRef]

10. Koutsias, N.; Xanthopoulos, G.; Founda, D.; Xystrakis, F.; Nioti, F.; Pleniou, M.; Mallinis, G.; Arianoutsou, M. On the relationships between forest fires and weather conditions in Greece from long-term national observations (1894-2010). Int. J. Wildland Fire 2013, 22, 493-507. [CrossRef]

11. Giannaros, T.M.; Kotroni, V.; Lagouvardos, K. Climatology and trend analysis (1987-2016) of fire weather in the Euro-Mediterranean. Int. J. Clim. 2020. [CrossRef]

12. Pereira, M.G.; Parente, J.; Amraoui, M.; Oliveira, A.; Fernandes, P.M. The role of weather and climate conditions on extreme wildfires. In Extreme Wildfire Events and Disasters; Elsevier: Amsterdam, The Netherlands, 2020; pp. 55-72. [CrossRef]

13. Barbero, R.; Abatzoglou, J.T.; Larkin, N.K.; Kolden, C.A.; Stocks, B. Climate change presents increased potential for very large fires in the contiguous United States. Int. J. Wildland Fire 2015, 24, 892. [CrossRef]

14. Wang, X.; Thompson, D.K.; Marshall, G.A.; Tymstra, C.; Carr, R.; Flannigan, M.D. Increasing frequency of extreme fire weather in Canada with climate change. Clim. Chang. 2015, 130, 573-586. [CrossRef]

15. Amatulli, G.; Camia, A.; San-Miguel-Ayanz, J. Estimating future burned areas under changing climate in the EU-Mediterranean countries. Sci. Total. Environ. 2013, 450, 209-222. [CrossRef] [PubMed]

16. Pereira, M.G.; Calado, T.J.; DaCamara, C.C.; Calheiros, T. Effects of regional climate change on rural fires in Portugal. Clim. Res. 2013, 57, 187-200. [CrossRef]

17. European Environmental Agency. Impacts and Vulnerability in Europe 2016-An Indicator-Based Report. Available online: https://www.eea.europa.eu/publications/climate-change-impacts-and-vulnerability-2016 (accessed on 1 July 2020). 
18. Krawchuk, M.A.; Moritz, M.A. Constraints on global fire activity vary across a resource gradient. Ecology 2010, 92, 121-132. [CrossRef] [PubMed]

19. Pausas, J.G.; Ribeiro, E. The global fire-productivity relationship: Fire and productivity. Glob. Ecol. Biogeogr. 2013, 22, 728-736. [CrossRef]

20. Turco, M.; Von Hardenberg, J.; AghaKouchak, A.; Llasat, M.C.; Provenzale, A.; Trigo, R.M. On the key role of droughts in the dynamics of summer fires in Mediterranean Europe. Sci. Rep. 2017, 7, 81. [CrossRef]

21. Gudmundsson, L.; Rego, F.; Rocha, M.; Seneviratne, S. Predicting above normal wildfire activity in southern Europe as a function of meteorological drought. Environ. Res. Lett. 2014, 9, 084008. [CrossRef]

22. Karali, A.; Hatzaki, M.; Giannakopoulos, C.; Roussos, A.; Xanthopoulos, G.; Tenentes, V. Sensitivity and evaluation of current fire risk and future projections due to climate change: The case study of Greece. Nat. Hazards Earth Syst. Sci. 2014, 14, 143-153. [CrossRef]

23. Turco, M.; Llasat, M.C.; Von Hardenberg, J.; Provenzale, A. Climate change impacts on wildfires in a Mediterranean environment. Clim. Chang. 2014, 125, 369-380. [CrossRef]

24. Carvalho, A.C.; Carvalho, A.; Martins, H.; Marques, C.; Rocha, A.; Borrego, C.; Viegas, D.X.; Miranda, A.I. Fire weather risk assessment under climate change using a dynamical downscaling approach. Environ. Model. Softw. 2011, 26, 1123-1133. [CrossRef]

25. Harris, S.; Anderson, W.; Kilinc, M.; Fogarty, L. The relationship between fire behavior measures and community loss: An exploratory analysis for developing a bushfire severity scale. Nat. Hazards 2012, 63, 391-415. [CrossRef]

26. Tedim, F.; Leone, V.; Coughlan, M.; Bouillon, C.; Xanthopoulos, G.; Royé, D.; Correia, F.J.M.; Ferreira, C. Extreme wildfire events: The definition. In Extreme Wildfire Events and Disasters; Elsevier BV: Amsterdam, The Netherlands, 2020; pp. 3-29.

27. Scott, J.H.; Reinhardt, E.D. Assessing Crown Fire Potential by Linking Models of Surface and Crown Fire Behavior; Res. Pap. RMRS-RP-29; U.S. Department of Agriculture, Forest Service, Rocky Mountain Research Station: Fort Collins, CO, USA, 2001; p. 59.

28. Reinhardt, E.D.; Crookston, N.L. The Fire and Fuels Extension to the Forest Vegetation Simulator; Gen. Tech. Rep. RMRS-GTR-116; U.S. Department of Agriculture, Forest Service, Rocky Mountain Research Station: Ogden, UT, USA, 2003; p. 209.

29. Finney, M.A. FARSITE: Fire Area Simulator-Model Development and Evaluation; Res. Pap. RMRSRP-4 Revised; U.S. Department of Agriculture, Forest Service, Rocky Mountain Research Station: Fort Collins, CO, USA, 2004.

30. Fuels Management Analyst Plus Software, Version 3. Available online: http://www.fireps.com/fmanalyst3/ index.htm (accessed on 9 April 2020).

31. Finney, M.A. An overview of FlamMap fire modelling capabilities. In Fuels Management_-How to Measure Success: Conference Proceedings; Proc. RMRS-P-41; U.S. Department of Agriculture, Forest Service, Rocky Mountain Research Station: Fort Collins, CO, USA, 2006; pp. 213-220.

32. Andrews, P.L.; Bevins, C.D.; Seli, R.C. BehavePlus Fire Modeling System, Version 4.0: User's Guide; Gen. Tech. Rep. RMRS-GTR-106WWW; U.S. Department of Agriculture, Forest Service, Rocky Mountain Research Station: Fort Collins, CO, USA, 2008; p. 116.

33. Ager, A.A.; Vaillant, N.M.; Anderson, J.; Miller, L. ArcFuels User Guide: For Use with ArcGIS 9.X; U.S. Department of Agriculture, Forest Service, Pacific Northwest Research Station, Western Wildland Environmental Threat Assessment Center: Prineville, OR, USA, 2011; p. 256.

34. Pence, M.; Zimmerman, T. The Wildland Fire Decision Support System: Integrating science, technology, and fire management. Fire Manag. Today 2011, 71, 18-22.

35. Taylor, S.W.; Pike, R.G.; Alexander, M.E. Field Guide to the Canadian Forest Fire Behavior Prediction (FBP) System; Spec. Publ. 11; Natural Resources Canada, Canadian Forest Service, Northern Forestry Centre: Edmonton, AB, Canada, 1997; p. 60.

36. Wotton, B.M.; Alexander, M.E.; Taylor, S.W. Updates and Revisions to the 1992 Canadian Forest Fire Behavior Prediction System; Inf. Rep. GLC-X-10. Sault Ste. Marie; Natural Resources Canada, Canadian Forest Service, Great Lakes Forestry Centre: Sault Ste. Marie, ON, Canada, 2009; p. 45.

37. Van Wagner, C.E. Development and Structure of the Canadian Forest Fire Weather Index System. In Technical Report 35; Canadian Forestry Service, Headquarters, Forestry: Ottawa, ON, Canada, 1987; p. 37. 
38. Tymstra, C.; Bryce, R.W.; Wotton, B.M.; Taylor, S.W.; Armitage, O.B. Development and Structure of Prometheus: The Canadian Wildland Fire Growth Simulation Model; Natural Resources Canada, Canadian Forest Service, Northern Forestry Centre: Edmonton, AB, Canada, 2010; p. 102.

39. Sakellariou, S.; Tampekis, S.; Samara, F.; Sfougaris, A.; Christopoulou, O. Review of state-of-the-art decision support systems (DSSs) for prevention and suppression of forest fires. J. For. Res. 2017, 28, 1107-1117. [CrossRef]

40. Groisman, P.; Sherstyukov, B.G.; Razuvaev, V.N.; Knight, R.W.; Enloe, J.G.; Stroumentova, N.S.; Whitfield, P.H.; Førland, E.; Hannsen-Bauer, I.; Tuomenvirta, H.; et al. Potential forest fire danger over Northern Eurasia: Changes during the 20th century. Glob. Planet. Chang. 2007, 56, 371-386. [CrossRef]

41. Fosberg, M.A. Weather in wildland fire management: The fire weather index. In Proceedings of the Conference on Sierra Nevada Meteorology, South Lake Tahoe, CA, USA, 19-21 June 1978; pp. 1-4.

42. McArthur, A.G. Fire behaviour in eucalypt forests: Forestry and Timber Bureau Leaflet 107. In Commonwealth of Australia; Forestry and Timber Bureau: Canberra, Australia, 1967; p. 25.

43. Eastaugh, C.; Hasenauer, H. Deriving forest fire ignition risk with biogeochemical process modelling. Environ. Model. Softw. 2014, 55, 132-142. [CrossRef]

44. Willis, C.; van Wilgen, B.; Tolhurst, K.; Everson, C.; D'Abreton, P.; Pero, L.; Fleming, G. The Development of a National Fire Danger Rating System for South Africa; Department of Water Affairs and Forestry: Pretoria, South Africa, 2011. [CrossRef]

45. Haines, D.A.; Main, W.A.; Frost, J.S.; Simard, A.J. Fire danger ratings and wildfire occurrence in the Northeastern United States. For. Sci. 1983, 29, 19-26.

46. Mckee, T.B.; Doesken, N.J.; Kleist, J. The Relationship of Drought Frequency and Duration Times Scales. In Proceedings of the 8th Conference on Applied Climatology, Anaheim, CA, USA, 17-22 January 1993; pp. 179-184.

47. Papagiannaki, K.; Giannaros, T.M.; Lykoudis, S.; Kotroni, V.; Lagouvardos, K. Weather-related thresholds for wildfire danger in a Mediterranean region: The case of Greece. Agric. For. Meteorol. 2020, 291, 108076. [CrossRef]

48. Giannaros, T.M.; Kotroni, V.; Lagouvardos, K.; Matzarakis, A. Climatology and trends of the Euro-Mediterranean thermal bioclimate. Int. J. Clim. 2018, 38, 3290-3308. [CrossRef]

49. Verdú, F.; Salas, J.; Vega-Garcia, C. A multivariate analysis of biophysical factors and forest fires in Spain, 1991-2005. Int. J. Wildland Fire 2012, 21, 498-509. [CrossRef]

50. Chandler, C.; Cheney, P.; Thomas, P.; Trabaud, L.; Williams, D. Fire in Forestry In Forest Fire Behavior and Effects, Volume 1.; John Wiley and Sons: New York, NY, USA, 1983; p. 450.

51. Chuvieco, E.; Allgöwer, B.; Salas, F.J. Integration of Physical and Human Factors in Fire Danger Assessment. In Wildland Fire Danger Estimation and Mapping. The Role of Remote Sensing Data; Chuvieco, E., Ed.; World Scientific Publishing: Singapore, 2013; pp. 197-218.

52. Deeming, J.E.; Lancaster, J.W.; Fosberg, M.A.; Furman, R.W.; Schroeder, M.J. The National Fire-Danger Rating System. Research PaperRM-84; Department of Agriculture, Forest Service, Rocky Mountain Research Station: Fort Collins, CO, USA, 1974; p. 165.

53. Stoyanova, J.S.; Georgiev, C.G.; Neytchev, P.N.; Kulishev, A.T. Quality Monitoring and Application of Fire Danger Index (FDI), a New Version of the LSA-SAF Fire Risk Map (FRM) Product for Eastern Mediterranean (Bulgaria). Internal Report of the EUMETSAT LSA-SAF CDOP-3 Project; EUMETSAT: Darmstadt, Germany, 2018.

54. Stoyanova, J.S.; Georgiev, C.G.; Neytchev, P.N.; Popova, M. From Drought to Fire Risk Warning (Site/Regional Scale). Internal Report of the EUMETSAT Internal Report on EUMETSAT SALGEE Project 2014-2015; Purchase order 4500010438/29-January-2014; EUMETSAT: Darmstadt, Germany, 2015.

55. Stoyanova, J.S. Information system for land surface status and fire danger over Bulgaria. In Proceedings of the European Forest Fire Monitoring Using Information Systems (EFFMIS) INTERREG IVC Project Meeting, Borovets, Bulgaria, 24-25 February 2011.

56. Stoyanova, J.S.; Georgiev, C.G. SVAT modeling in support to flood risk assessment. Atmos Res. 2013, 123, 384-399. [CrossRef]

57. Trigo, I.F.; Dacamara, C.C.; Viterbo, P.; Roujean, J.-L.; Olesen, F.; Barroso, C.; Camacho-De-Coca, F.; Carrer, D.; Freitas, S.C.; García-Haro, F.; et al. The Satellite Application Facility for Land Surface Analysis. Int. J. Remote Sens. 2011, 32, 2725-2744. [CrossRef] 
58. Pinto, M.M.; Dacamara, C.C.; Trigo, I.F.; Trigo, R.M.; Turkman, K.F. Fire danger rating over Mediterranean Europe based on fire radiative power derived from Meteosat. Nat. Hazards Earth Syst. Sci. 2018, 18, 515-529. [CrossRef]

59. Stoyanova, J.S.; Georgiev, C.G.; Neytchev, P.N.; Vladimirov, E.V. Combined assessment of terrestrial drought and atmospheric conditions through a composite index for fire risk forecast. In Proceedings of the 2016 EUMETSAT Meteorological Satellite Conference, Darmstadt, Germany, 26-30 September 2016.

60. Xiao, J.; Zhuang, Q. Drought effects on large fire activity in Canadian and Alaskan forests. Environ. Res. Lett. 2017, 2, 44003. [CrossRef]

61. Pausas, J.G.; Fernández-Muñoz, S. Fire regime changes in the Western Mediterranean Basin: From fuel-limited to drought-driven fire regime. Clim. Chang. 2011, 110, 215-226. [CrossRef]

62. Palmer, T.N.; Anderson, D.L.T. The prospects for seasonal forecasting-A review paper. Q. J. R. Meteorol. Soc. 1994, 120, 755-793. [CrossRef]

63. Saha, S.; Moorthi, S.; Wu, X.; Wang, J.; Nadiga, S.; Tripp, P.; Behringer, D.; Hou, Y.-T.; Chuang, H.-Y.; Iredell, M.; et al. The NCEP Climate Forecast System Version 2. J. Clim. 2014, 27, 2185-2208. [CrossRef]

64. Bedia, J.; Golding, N.; Casanueva, A.; Iturbide, M.; Buontempo, C.; Gutierrez, J. Seasonal predictions of Fire Weather Index: Paving the way for their operational applicability in Mediterranean Europe. Clim. Serv. 2018, 9, 101-110. [CrossRef]

65. Christensen, J.H.; Boberg, F.; Christensen, O.B.; Lucas-Picher, P. On the need for bias correction of regional climate change projections of temperature and precipitation. Geophys. Res. Lett. 2008, 35, 20709. [CrossRef]

66. Siegmund, J.; Bliefernicht, J.; Laux, P.; Kunstmann, H. Toward a seasonal precipitation prediction system for West Africa: Performance of CFSv2 and high-resolution dynamical downscaling. J. Geophys. Res. Atmos. 2015, 120, 7316-7339. [CrossRef]

67. Luo, L.; Wood, E. Use of Bayesian Merging Techniques in a Multimodel Seasonal Hydrologic Ensemble Prediction System for the Eastern United States. J. Hydrometeorol. 2008, 9, 866-884. [CrossRef]

68. Yuan, X.; Wood, E.; Roundy, J.K.; Pan, M. CFSv2-Based Seasonal Hydroclimatic Forecasts over the Conterminous United States. J. Clim. 2013, 26, 4828-4847. [CrossRef]

69. Eumetsat. Active Fire Monitoring: Product Guide Doc. No.: EUM/TSS/MAN/15/801989, Issue: v1C; Eumetsat: Darmstadt, Germany, 2015; p. 11.

70. Eumetsat. Product User Manual Fire Radiative Power; SAF/LAND/KCL/PUM_FRP/2.2 Issue/Revision Index: Issue 1; Eumetsat: Darmstadt, Germany, 2016; p. 48.

71. Eumetsat. Product User Manual Fire Detection and Monitoring (FDEM); SAF/LAND/IDL/PUM_FD\&M/2.1 Issue/Revision Index: Issue 2.1; Eumetsat: Darmstadt, Germany, 2016; p. 24.

72. Amraoui, M.; Dacamara, C.C.; Pereira, J. Detection and monitoring of African vegetation fires using MSG-SEVIRI imagery. Remote Sens. Environ. 2010, 114, 1038-1052. [CrossRef]

73. Kuenzer, C.; Dech, S. Thermal Infrared Remote Sensing: Sensors, Methods, Applications; Springer: Dordrecht, The Netherlands, 2013; p. 537. [CrossRef]

74. Giannaros, T.M.; Kotroni, V.; Lagouvardos, K. IRIS-Rapid response fire spread forecasting system: Development, calibration and evaluation. Agric. For. Meteorol. 2019, 279, 107745. [CrossRef]

75. Salis, M.; Arca, B.; Alcasena, F.; Arianoutsou, M.; Bacciu, V.; Duce, P.; Duguy, B.; Koutsias, N.; Mallinis, G.; Mitsopoulos, I.; et al. Predicting wildfire spread and behavior in Mediterranean landscapes. Int. J. Wildland Fire 2016, 25, 1015-1032. [CrossRef]

76. Congalton, R.G. A review of assessing the accuracy of classifications of remotely sensed data. Remote Sens. Environ. 1991, 37, 35-46. [CrossRef]

77. Sorensen, T.A. A method of establishing groups of equal amplitude in plant sociology based on similarity of species content, and its application to analysis of the vegetation on Danish commons. K. Dan. Vidensk. Selsk. Biol. Skr. 1948, 5, 1-34.

78. Salis, M. Fire Behavior Simulation in Mediterranean Maquis Using FARSITE (Fire Area Simulator). Ph.D. Thesis, Universita degli Studi di Sassari, Sassari, Italy, 2008; p. 77.

79. Strandberg, G.; Bärring, A.; Hansson, U.; Jansson, C.; Jones, C.; Kjellström, E. CORDEX Scenarios for Europe from the Rossby Centre Regional Climate Model RCA4, Report Meteorology and Climatology, 116, SMHI internal report, SE-60176; Norrköping, Sverige, 2014; p. 84. Available online: https://www.smhi.se/ polopoly_fs/1.90273!/Menu/general/extGroup/attachmentColHold/mainCol1/file/RMK_116.pdf (accessed on 17 August 2020). 
80. Collins, W.J.; Bellouin, N.; Doutriaux-Boucher, M.; Gedney, N.; Halloran, P.; Hinton, T.; Woodward, S. Development and evaluation of an Earth-System model-HadGEM2. Geosci. Model. Dev. 2011, 4, 1051-1075. [CrossRef]

81. Martin, G.M.; Milton, S.F.; Senior, C.A.; Brooks, M.; Ineson, S.; Reichler, T.; Kim, J. Analysis and Reduction of Systematic Errors through a Seamless Approach to Modeling Weather and Climate. J. Clim. 2010, 23, 5933-5957. [CrossRef]

82. Popke, D.; Stevens, B.; Voigt, A. Climate and climate change in a radiative-convective equilibrium version of ECHAM6. J. Adv. Model. Earth Syst. 2012, 5, 1-14. [CrossRef]

83. Voldoire, A.; Sanchez-Gomez, E.; Melia, D.S.Y.; Decharme, B.; Cassou, C.; Senesi, S.; Valcke, S.; Beau, I.; Alias, A.; Chevallier, M.; et al. The CNRM-CM5.1 global climate model: Description and basic evaluation. Clim. Dyn. 2012, 40, 2091-2121. [CrossRef]

84. Mandel, J.; Amram, S.; Beezley, J.D.; Kelman, G.; Kochanski, A.K.; Kondratenko, V.Y.; Lynn, B.H.; Regev, B.; Vejmelka, M. Recent advances and applications of WRF-SFIRE. Nat. Hazards Earth Syst. Sci. 2014, 14, 2829-2845. [CrossRef]

85. Jiménez, P.A.; Muñoz-Esparza, D.; Kosović, B. A High Resolution Coupled Fire-Atmosphere Forecasting System to Minimize the Impacts of Wildland Fires: Applications to the Chimney Tops II Wildland Event. Atmosphere 2018, 9, 197. [CrossRef]

86. Filippi, J.-B.; Bosseur, F.; Mari, C.; Lac, C. Simulation of a Large Wildfire in a Coupled Fire-Atmosphere Model. Atmosphere 2018, 9, 218. [CrossRef]

(C) 2020 by the authors. Licensee MDPI, Basel, Switzerland. This article is an open access article distributed under the terms and conditions of the Creative Commons Attribution (CC BY) license (http://creativecommons.org/licenses/by/4.0/). 